\title{
Mechanisms behind sulfur promoted oxidation of methane
}

\author{
Djamela Bounechada, ${ }^{a, b}$ Sheedeh Fouladvand,,$^{a, c}$ Lisa Kylhammar, ${ }^{a, c}$ Torben Pingel, ${ }^{a, d}$ Eva \\ Olsson, ${ }^{a, d}$ Magnus Skoglundh, ${ }^{a, c}$ Johan Gustafson, ${ }^{e}$ Marco Di Michiel, ${ }^{f}$ Mark A. Newton ${ }^{f}$ and Per- \\ Anders Carlsson $* a, c$
}

\author{
Received Xth $X X X X X X X X X X 20 X X$, Accepted Xth $X X X X X X X X X 20 X X$ \\ First published on the web Xth $X X X X X X X X X X 200 X$ \\ DOI: 10.1039/b000000x
}

The promoting effect of $\mathrm{SO}_{2}$ on the activity for methane oxidation over platinum supported on silica, alumina and ceria has been studied by flow-reactor, in situ infrared spectroscopy and in situ high-energy x-ray diffraction experiments under transient reaction conditions. The catalytic activity is clearly dependent on the support material and its interaction with the noble metal both in absence and presence of sulfur. On platinum, the competitive reactant adsorption favors oxygen dissociation such that oxygen self-poisoning is observed for Pt/silica and Pt/alumina. Contrarily for Pt/ceria, no oxygen self-poisoning is observed, which seems to be due to additional reaction channels via sites on the platinum-ceria boundary and/or ceria surface considerably far from the Pt crystallites. Addition of sulfur dioxide generally leads to the formation of ad-SO $\mathrm{S}_{x}$ species on the supports with a concomitant removal and/or blockage/rearrangement of surface hydroxyl groups. Thereby, the methane oxidation is inhibited for $\mathrm{Pt} /$ silica, enhanced for Pt/alumina and temporary enhanced followed by inhibition after long-term exposure to sulfur for Pt/ceria. The observations can be explained by competitive oxidation of $\mathrm{SO}_{2}$ and $\mathrm{CH}_{4}$ on Pt/silica, formation of new active sites at the noble metal-support interface promoting dissociative adsorption of methane on Pt/alumina, and in the case of Pt/ceria, formation of promoting interfacial surface sulfates followed by formation of deactivating bulk-like sulfate species. Furthermore, it can be excluded that reduction of detrimental high oxygen coverage and/or oxide formation on the platinum particles through $\mathrm{SO}_{2}$ oxidation is the main cause for the promotional effects observed.

\section{Introduction}

The growing need to diversify energy sources motivates the development of gas engines to utilize the huge worldwide natural gas resources for transportation purposes. By replacing common fuels like gasoline and diesel with natural gas, typically containing $90-95 \%$ of $\mathrm{CH}_{4}$, a net reduction of $\mathrm{CO}_{2}$ emissions can be achieved due to the low $\mathrm{C} / \mathrm{H}$ ratio of methane. Furthermore, this would also stimulate the production and use of biogas, which is a renewable non-fossil fuel. Despite these advantages there are still environmental challenges that need to be met. For example the levels of unburned methane present in the exhausts from natural gas fuelleed engines, typically up to $1000 \mathrm{ppm}$, must be lowered to comply with the emission legislations. One preferred technology for emission control is

a Competence Centre for Catalysis, Chalmers University of Technology, SE41296 Göteborg, Sweden.

${ }^{b}$ Dipartimento di Energia, Politecnico di Milano, 20133 Milano, Italy.

${ }^{c}$ Department of Chemical and Biological Engineering, Chalmers University of Technology, SE-412 96 Göteborg, Sweden.

${ }^{d}$ Department of Applied Physics, Chalmers University of Technology, SE-412 96 Göteborg, Sweden.

${ }^{e}$ Division of Synchrotron Radiation Research, Lund University, Box 118, SE22100, Sweden.

${ }^{f}$ ESRF, 6 rue Jules Horowitz -38000, Grenoble, France.

* Corresponding author e-mail: per-anders.carlsson@chalmers.se. catalytic aftertreatment of the exhausts. In the present case this is, however, especially challenging as methane is highly stable and thus difficult to catalytically activate for further reactions at the low temperatures representative of modern engine exhausts. Thus, catalytic concepts and technologies for efficient oxidation of methane at low temperatures need to be developed.

Generally, the rate-limiting step for methane oxidation is considered to be the abstraction of the first hydrogen in the dissociative adsorption of methane ${ }^{1}$. Therefore, catalysts that can dissociate methane readily are usually also efficient for total methane oxidation. The most active elements for total oxidation of methane presently known are the noble metals ${ }^{2}$. Supported palladium catalysts show the highest activity for methane oxidation at low temperatures in oxygen excess ${ }^{3,4}$. Unfortunately, palladium based catalysts may suffer from deactivation by sulfur containing compounds forming relatively stable palladium sulfates ${ }^{5,6}$. Furthermore, the presence of water, even the small amounts formed during methane oxidation under otherwise dry conditions ${ }^{7}$, have been found to inhibit the catalytic reaction ${ }^{5,8}$. This has been attributed to hydration of the palladium surfaces ${ }^{9}$. On the contrary, platinum is less sensitive towards these poisons ${ }^{5}$ but instead the overall activity is generally lower for Pt than for Pd under oxygen excess

This journal is @ The Royal Society of Chemistry [year] Journal Name, 2010, [vol], 1-16 |1 
due to oxygen self-poisoning $4,10,11$ and/or oxide formation on the Pt particles inhibiting the methane dissociation ${ }^{11-13}$. However, the inhibiting effect by oxygen on platinum can be circumvented by transient operation of the feed gas stoichiometry ${ }^{12-16}$.

It has been shown that sulfur dioxide can promote the methane oxidation over platinum supported on alumina ${ }^{17-19}$ and more recently also for platinum supported on ceria ${ }^{20}$. A similar promotional effect for propane oxidation over $\mathrm{Pt} /$ alumina has been observed in several studies ${ }^{21-28}$ as well as for $\mathrm{Ce}_{0.67} \mathrm{Zr}_{0.33} \mathrm{O}_{2}{ }^{29}$ and $\mathrm{Pt}(111)^{30}$. In the case of $\mathrm{Pt} /$ ceria, Kylhammar et al. ${ }^{20}$ observed a promotional effect between 300 and $450^{\circ} \mathrm{C}$ under lean (large oxygen excess) conditions, although as a function of time on stream the promoting effect diminishes and instead the methane oxidation becomes inhibited. On the basis of in situ infrared spectroscopy experiments it was shown that introduction of $\mathrm{SO}_{2}$ results in an immediate formation of sulfate species on ceria that is accompanied by a corresponding instantaneous increase in methane conversion. The results were discussed in terms of both breakage of oxygen self-poisoning/platinum oxides, effectively leading to a higher number of sites on $\mathrm{Pt}$ available for methane dissociation, and sulfate formation on ceria sites close to platinum that electronically can modify the platinum sites and/or form new sites at the noble metal-support interface. Such sites were considered to polarize the $\mathrm{C}-\mathrm{H}$ bond in methane facilitating the dissociative adsorption. Interestingly, the spectroscopic analysis shows that despite the lean conditions, the ceria is reduced upon $\mathrm{SO}_{2}$ exposure, indicating that oxidation of ceria with gas phase oxygen is kinetically hindered and that sulfate formation also may block spillover of oxygen that otherwise would oxidize the ceria. However, the mechanisms behind the promoting effect seem even more complex and the role of the support is not clear. For example, oxygen spillover can decrease the oxygen coverage and/or induce rearrangement of adsorbates on the platinum surface and thereby facilitate the dissociative adsorption of methane on Pt. Thus sulfation of sites located at the noble metal-support boundary as formation of new sites may not solely explain the observed promoting effect but may also influence the reaction dynamics, especially processes related to spillover. The latter, for example, was proposed to lead to a settled oxygen dynamics in the platinum-ceria system, which can explain the long-term poisoning effect of sulfur.

Here we study the role of the support material and the noble metal-support interaction in sulfur promoted low-temperature oxidation of methane over platinum based catalysts. This is realized through a comparative investigation of the methane oxidation as a function of $\mathrm{SO}_{2}$ exposure over different catalytic systems i.e., platinum supported on silica, alumina and ceria, each having significantly different affinity for sulfur oxides $^{31,32}$. The relationship between catalyst structure and function is studied by use of in situ high-energy x-ray diffraction, in situ infrared spectroscopy and mass spectrometry. Particularly, and necessary for the present in situ experiments, the diffraction measurements utilize the high energy of the $\mathrm{x}$ rays for scattering within small angles (compressed $q$ space) such that time-resolved measurements can be realized. Furthermore, the high energy facilitates penetration of as heavy samples as Pt/ceria and even subtile changes in the samples can be followed accurately, which is necessary for studies of $\mathrm{SO}_{2}$ promoted methane oxidation *.

\section{Experimental section}

\subsection{Catalyst preparation and characterization}

Three types of supported platinum catalysts with a Pt loading of 4 wt.-\% were prepared by impregnation of $\mathrm{SiO}_{2}$ (Kromasil Silica KR-300-10, Akzo Nobel Eka Chemicals), $\mathrm{Al}_{2} \mathrm{O}_{3}$ (Puralox SBa 200, Sasol) and $\mathrm{CeO}_{2}$ (99.5 H.S.A. 514, RhônePoulenc) that first were pretreated in air at $600^{\circ} \mathrm{C}$ for 4 hours. Each support was dispersed in an aqueous solution consisting of distilled water and tetraammineplatinum(II)nitrate $\left(\left(\mathrm{NH}_{3}\right)_{4} \mathrm{Pt}\left(\mathrm{NO}_{3}\right)_{2}\right.$, Alfa Aesar GmbH \& Co. KG). For the $\mathrm{Pt} /$ ceria samples, the impregnation was carried out in three steps as to obtain the desired Pt loading. In order to increase the interaction between the platinum complex and the support, the $\mathrm{pH}$ of the solution was adjusted by $\mathrm{NH}_{4} \mathrm{OH}$ addition taking into account the isoelectric point of each oxide ${ }^{37}$. The obtained slurry was then stirred for 20 minutes, frozen with liquid nitrogen and freeze-dried for $12 \mathrm{~h}$. The resulting powder was finally calcined in air at $550^{\circ} \mathrm{C}$ for one hour (heating rate of $5^{\circ} \mathrm{C} / \mathrm{min}$ ).

Monolithic samples were prepared by immersing cordierite monoliths $(\varnothing=13 \mathrm{~mm}$, length $=15 \mathrm{~mm}, 400 \mathrm{cpsi}$, Corning Inc.) into a water slurry consisting of the powder catalyst and a binder. For the $\mathrm{Pt} /$ silica, Pt/alumina and $\mathrm{Pt} /$ ceria powder samples, colloidal silica (Bindzil, AkzoNobel Eka Chemicals), boehmite (Disperal P2, Sasol Germany GmbH) and colloidal ceria (Nyacol $\mathrm{CeO}_{2}(\mathrm{Ac})$, Nyacol Nano Technologies) was used as binder, respectively. The coated monoliths were then dried in air at $90^{\circ} \mathrm{C}$ for $10 \mathrm{~min}$ and calcined at $600^{\circ} \mathrm{C}$ for $2 \mathrm{~min}$ also in air. This procedure was repeated until $200 \mathrm{mg}$ of coating was attached to each sample. Finally, the samples were calcined in air at $550^{\circ} \mathrm{C}$ for one hour.

Using the BET method for $\mathrm{P} / \mathrm{P}_{0}=0.05-0.20$, the specific surface area for the Pt/silica, Pt/alumina and Pt/ceria powder samples were calculated to be 117,173 and $156 \mathrm{~m}^{2} / \mathrm{g}$, respectively. The Pt particle sizes of the different powder samples

\footnotetext{
* We mention that the present experiments are largely characterized by irreversible processes and thus demodulation analysis with phase sensitive detection $^{33-36}$ of diffraction features cannot be made as such analysis requires
} repeatable responses within the experiment. 
were studied by transmission electron microscopy (TEM). The TEM samples were prepared by morting the catalysts in an agate mortar and then placed on holey carbon film TEM grids. The samples were imaged using an FEI Titan 80-300 microscope with a probe Cs (spherical abberation) corrector operated at $300 \mathrm{kV}$ and using a high angle annular dark field (HAADF) scanning TEM imaging mode providing $\mathrm{Z}$ number contrast. The electron probe size used for these studies was about $0.2 \mathrm{~nm}$. Platinum particle size distributions were determined for each sample by measuring the projected areas of the particles and calculating diameters assuming circular shapes, so-called area diameters.

\subsection{Equipment for catalytic studies and in situ character- isation}

2.2.1 Continuous gas-flow reactor system. All experiments with monolith samples were performed using a continuous gas-flow reactor consisting of a horizontal quartz tube $(\varnothing=15 \mathrm{~mm}$, length $=600 \mathrm{~mm})$ surrounded by a metal coil (Kanthal) for resistive heating of the gas flow and the sample (effective heating length $=450 \mathrm{~mm}$ ). The coil was insulated with quartz wool (SUPERWOOL 607 HT, Thermal Ceramics) surrounded with an outer layer of aluminum foil. In order to reduce axial temperature gradients, the sample was placed in the isothermal zone of the reactor between two blank cordierite monoliths functioning as heat radiation shields ${ }^{38}$. The monoliths were of the same size $(\varnothing=13 \mathrm{~mm}$, length $=$ $15 \mathrm{~mm}, 400 \mathrm{cpsi}$ ) and separated by smaller cordierite monoliths (three by three channels, length $=5 \mathrm{~mm}, 400 \mathrm{cpsi}$ ). The inlet gas temperature was measured by one fixed thermocouple (k-type, Pentronic), placed in the central channel of the upstream cordierite monolith $12 \mathrm{~mm}$ from the catalyst front, and controlled with a PID regulator (Eurotherm 3508). The temperatures in the sample monolith and in the two downstream cordierite monoliths were measured by individual thermocouples. The gas composition, i.e., $\mathrm{CH}_{4}, \mathrm{O}_{2}, \mathrm{SO}_{2}$ and $\mathrm{Ar}$ flows, was composed using individual mass flow controllers (Bronkhorst LOW- $\Delta \mathrm{P}$-FLOW) for theses gases and finally introduced to the reactor via three air actuated four-way pulse valves (Valco, VICI), which allows for rapid changes of the feed composition. The outlet gas composition was analyzed by mass spectrometry (Airsense Compact, V\&F). The ionmolecule reaction (IMR) method was used to follow the mass to charge ratio $(\mathrm{m} / \mathrm{z}) 64\left(\mathrm{SO}_{2}\right)$ using xenon for ionization, whereas m/z $2\left(\mathrm{H}_{2}\right), 15\left(\mathrm{CH}_{4}\right), 18\left(\mathrm{H}_{2} \mathrm{O}\right), 28(\mathrm{CO}), 32\left(\mathrm{O}_{2}\right.$ and $\mathrm{S}), 33$ (HS), $44\left(\mathrm{CO}_{2}\right)$ and 48 (SO) were measured through the electron impact (EI) method. The $\mathrm{m} / \mathrm{z} 80\left(\mathrm{SO}_{3}\right)$ could not be detected satisfactorily with the present reactor set-up.

2.2.2 Combined in situ Fourier transform infrared spectroscopy and mass spectrometry system. The in situ Fourier transformed infrared (FTIR) spectroscopy measure- ments were performed with powder samples in diffuse reflectance mode (DRIFT) using a Bio-Rad FTS6000 spectrometer equipped with a high-temperature reaction cell (Harrick Scientific, Praying Mantis) with $\mathrm{KBr}$ windows and an MCT detector. The temperature of the sample holder was measured with a thermocouple (k-type) and controlled with a PID regulator (Eurotherm 2416). Individual mass flow controllers (Bronkhorst LOW- $\Delta \mathrm{P}-\mathrm{FLOW}$ ) were used to introduce the gases. Moreover, to facilitate precise transients, the $\mathrm{SO}_{2}$ feed was introduced via an air actuated high-speed gas valve (Valco, VICI). The outlet gas composition was analyzed by mass spectrometry (Balzers QuadStar 420) following the $\mathrm{m} / \mathrm{z}$ $2\left(\mathrm{H}_{2}\right), 15\left(\mathrm{CH}_{4}\right), 18\left(\mathrm{H}_{2} \mathrm{O}\right), 28(\mathrm{CO}), 32\left(\mathrm{O}_{2}\right.$ and $\left.\mathrm{S}\right), 33(\mathrm{HS})$, $34\left(\mathrm{H}_{2} \mathrm{~S}\right), 40(\mathrm{Ar}), 44\left(\mathrm{CO}_{2}\right), 48(\mathrm{SO}), 64\left(\mathrm{SO}_{2}\right) 80\left(\mathrm{SO}_{3}\right), 81$ $\left(\mathrm{SO}_{3}\right), 82\left(\mathrm{SO}_{3}\right)$ and $83\left(\mathrm{SO}_{3}\right)$.

2.2.3 Synchronous in situ high-energy x-ray diffraction, in situ Fourier transformed infrared spectroscopy and mass spectrometry system. The synchronous, timeresolved, high-energy x-ray diffraction (HE-XRD), DRIFTS and MS measurements were performed in situ at beamline ID15B at the European Synchrotron Radiation Facility (ESRF) in Grenoble, France. For the simultaneous HEXRD/DRIFTS/MS measurements a modified TA Spectratech reaction cell was used. The dimensions of the sample cup were $3 \mathrm{~mm}$ in diameter and $2.5 \mathrm{~mm}$ deep. The gas delivery system and sample environment, which have been described in detail elsewhere ${ }^{39,40}$, are designed for precise transient studies through the combination of air actuated high-speed gas valves (Valco, VICI) and a small reactor volume facilitating rapid gas composition changes over the catalyst sample. For the HEXRD measurements, an energy of $86.8 \mathrm{keV}$, corresponding to a wavelength of $0.143 \AA$, and an energy resolution $(\Delta \mathrm{E} / \mathrm{E})$ of about $1.4 \times 10^{-3}$ were used. The HE-XRD patterns were collected at a frequency of $2 \mathrm{~Hz}$ with an exposure time of $400 \mathrm{~ms}$ (100 ms detector readout time) using a digital flat-panel x-ray detector (Pixium 4700). The DRIFT spectra were recorded using a Bruker IFS infrared spectrometer equipped with a high sensitivity narrow band MCT detector. The product stream was analyzed by mass spectrometry (Pfeiffer, Prisma) following the $\mathrm{m} / \mathrm{z}$ signals $2\left(\mathrm{H}_{2}\right), 4(\mathrm{He}), 15\left(\mathrm{CH}_{4}\right), 28(\mathrm{CO}), 32\left(\mathrm{O}_{2}\right)$, $44\left(\mathrm{CO}_{2}\right)$ and $64\left(\mathrm{SO}_{2}\right)$.

\subsection{Experimental procedures}

2.3.1 Catalytic studies in continuous gas-flow reactor. In order to achieve a common starting point for the experiments, the samples were pretreated with 8 vol.- $\% \mathrm{O}_{2}$ and 500 vol.-ppm $\mathrm{CH}_{4}$ (in the following vol.- $\%$ and vol.-ppm are denoted $\%$ and ppm, respectively) at $500^{\circ} \mathrm{C}$ for one hour using a total flow of $500 \mathrm{ml} / \mathrm{min}$ corresponding to a space velocity (GHSV) of $15000 \mathrm{~h}^{-1}$. This GHSV was kept constant and Ar was used as carrier gas in all flow-reactor experiments de- 
scribed in more detail below. The temperature programmed reaction (TPReaction) experiments, starting with pretreated samples, were performed by decreasing the temperature by $5^{\circ} \mathrm{C} / \mathrm{min}$ from 500 to $100^{\circ} \mathrm{C}$, dwelling for $20 \mathrm{~min}$ and then increasing the temperature to $500^{\circ} \mathrm{C}$ and dwelling for another 20 min using the same gas composition. This cooling-heating cycle was repeated three times (cycle 1-3) followed by another three cycles (cycle 4-6) where $20 \mathrm{ppm} \mathrm{SO}_{2}$ was added to the feed and, finally, by three cycles (cycle 7-9) without $\mathrm{SO}_{2}$ ( $c f$. schematic in Fig. 2). The transient $\mathrm{SO}_{2}$ exposure experiments were performed using pretreated samples by introducing 500 ppm $\mathrm{CH}_{4}$ and $1500 \mathrm{ppm} \mathrm{O}_{2}$ at the temperature to be studied, i.e. 400 and $500^{\circ} \mathrm{C}$, for $60 \mathrm{~min}$. Subsequently, the $\mathrm{SO}_{2}$ exposure experiment was started by instantly introducing $100 \mathrm{ppm}$ $\mathrm{SO}_{2}$ for a duration of $5 \mathrm{~min}$ to the feed and the response was followed until $25 \mathrm{~min}$ after the sulfur exposure period. In total, this sequence was repeated 24 times, which corresponds to $2 \mathrm{~h}$ of $\mathrm{SO}_{2}$ exposure.
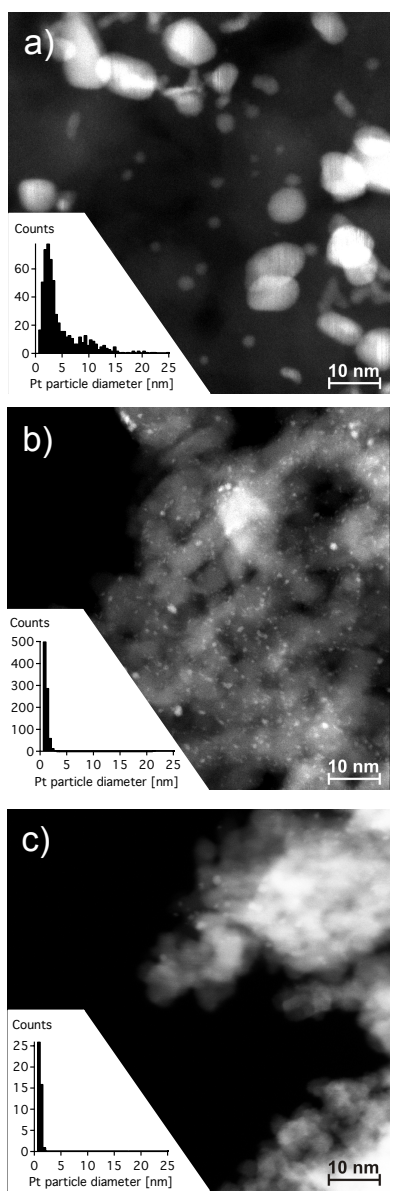

Fig. 1 STEM micrographs for the as prepared a) $4 \%$ Pt/silica, b) $4 \%$ $\mathrm{Pt} /$ alumina and c) $4 \% \mathrm{Pt} /$ ceria samples. The inserts show the $\mathrm{Pt}$ particle size distribution.
2.3.2 In situ DRIFTS/MS experiments. For each DRIFTS experiment, a new powder sample from the same preparation batch was used. The silica and alumina containing samples were diluted by natural diamond (Alfa Aesar GmbH $\&$ Co KG) using a catalyst:dilutant wt.-ratio of 1:4. The sample was pretreated with $8 \% \mathrm{O}_{2}$ and $500 \mathrm{ppm} \mathrm{CH}_{4}$ at $500^{\circ} \mathrm{C}$ for one hour using a total flow of $100 \mathrm{ml} / \mathrm{min}$. The wavenumber region $4000-1000 \mathrm{~cm}^{-1}$ was investigated with a spectral resolution of $1 \mathrm{~cm}^{-1}$. The transient $\mathrm{SO}_{2}$ exposure experiments were performed with pretreated samples by introducing 500 ppm $\mathrm{CH}_{4}$ and $1500 \mathrm{ppm} \mathrm{O}_{2}$ in $\mathrm{Ar}$ at $500^{\circ} \mathrm{C}$ after which the desired reaction temperature, i.e., 400 and $500^{\circ} \mathrm{C}$, was established for $30 \mathrm{~min}$. Subsequently, the experiment was started by introducing pulses of $\mathrm{SO}_{2}$ ( $40 \mathrm{ppm}$ for $5 \mathrm{~min}$ ) into the feed and the response was followed for 20 min thereafter. This sequence was repeated four times after which the sample was exposed to $\mathrm{SO}_{2}$ for $60 \mathrm{~min}$, in total corresponding to $80 \mathrm{~min}$ with $\mathrm{SO}_{2}$ exposure. The reference spectrum used for background subtraction was recorded in the reaction mixture 10 min before the first $\mathrm{SO}_{2}$ pulse. Sample spectra were then collected each second for the first $\mathrm{SO}_{2}$ pulse and every $30 \mathrm{~s}$ for the remaining pulses.

2.3.3 In situ HE-XRD/DRIFTS/MS experiments. For each experiment, a new powder sample from the same preparation batch was used. About $40 \mathrm{mg}$ of the catalyst sample was loaded into the sample cup. The sample was pretreated with $1.5 \% \mathrm{O}_{2}$ and $1000 \mathrm{ppm} \mathrm{CH}_{4}$ at $350^{\circ} \mathrm{C}$ for 10 min using a total flow of $100 \mathrm{ml} / \mathrm{min}$. The experiment was then started by introducing ten $0.05 \% \mathrm{SO}_{2}$ pulses with a duration of $75 \mathrm{~s}$ separated by a $75 \mathrm{~s}$ period with only $\mathrm{CH}_{4} / \mathrm{O}_{2} / \mathrm{He}$. The $\mathrm{HE}$ XRD/DRIFTS measurements were triggered by the first $\mathrm{SO}_{2}$ pulse.

\section{Results}

\subsection{Analysis of STEM images}

Fig. 1a-c shows representative STEM images of the as prepared Pt/silica, Pt/alumina and Pt/ceria samples, respectively. The insert in each panel shows the Pt particle size distribution (PSD) of the sample. The Pt/silica sample (Fig. 1a) shows a wide modal Pt PSD in the range 0.5-20 nm. Platinum particles from one to ten $\mathrm{nm}$ in diameter are clearly visible in the micrograph. About $40 \%$ of the platinum particles are smaller than three $\mathrm{nm}$. The Pt PSD for the Pt/alumina sample (Fig. 1b) is narrow with $99 \%$ of the particles below three nm. Also a few larger particles, up to $20 \mathrm{~nm}$, are present although not visible in the present image. Finally, in the Pt/ceria sample (Fig. 1c) the platinum particles are considerably more difficult to discern due to the low contrast between the platinum and ceria. However, the Pt PSD is narrow also in this case and the majority of the Pt particles are smaller than one to three $\mathrm{nm}$ in

4 | Journal Name, 2010, [vol],1-16

This journal is $\odot$ The Royal Society of Chemistry [year] 

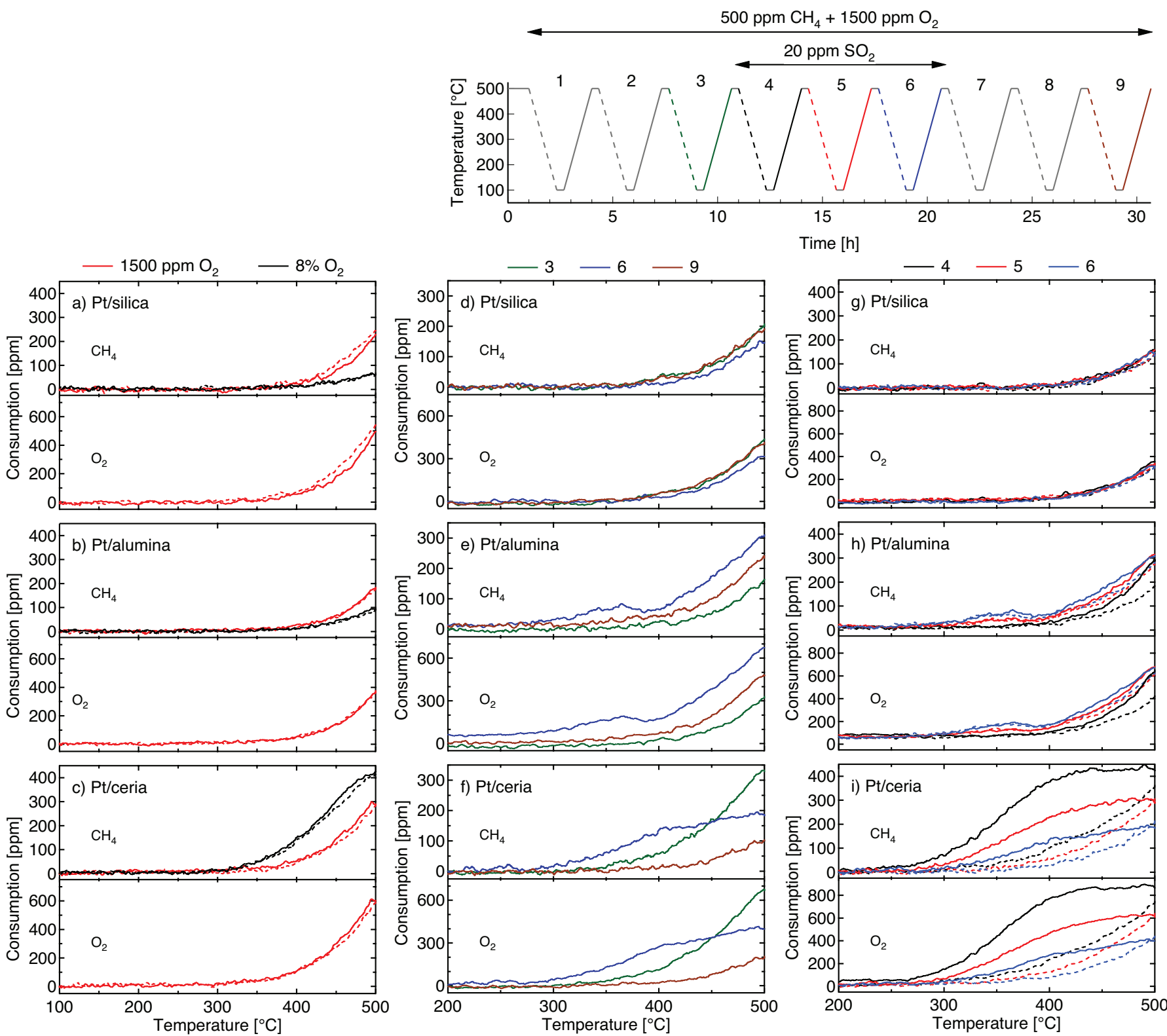

Fig. 2 Temperature programmed reaction of $500 \mathrm{ppm} \mathrm{CH}_{4}$ over $4 \% \mathrm{Pt} /$ silica, $4 \% \mathrm{Pt} /$ alumina and $4 \% \mathrm{Pt} /$ ceria during cooling (dashed lines) and heating (solid lines). The ramp rate for both cooling and heating is $5^{\circ} \mathrm{C} / \mathrm{min}$ and the GHSV is $15000 \mathrm{~h}^{-1}$. Panel a)-c) show the influence

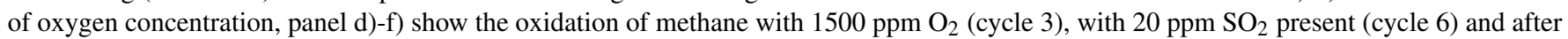
$\mathrm{SO}_{2}$ exposure (cycle 9) and panel g)-i) the oxidation in the presence of $20 \mathrm{ppm} \mathrm{SO}_{2}$ (cycle 4-6) The color code for the consecutive cycle numbers is indicated according to the experiment schematic shown at the top. 
diameter. As for the Pt/alumina sample a few larger particles (about $20 \mathrm{~nm}$ ) can be discerned. We mention that due to the low contrast between platinum and ceria a significantly lower number of particles was counted, which of course influences the statistics for this sample correspondingly. The analysis of the STEM images can be used for estimating the average Pt dispersion. Following the procedure proposed by Borodziński et $a l .{ }^{41}$, and using the Pt PSDs reported here, an average Pt dispersion was calculated to be around $10 \%$ for all samples. It is important, however, to note that this value is largely biased by the very small number of large particles present in the samples. This explains the apparent discrepancy between the calculated dispersion and the micrographs, which in the case of Pt/alumina and $\mathrm{Pt} /$ ceria clearly suggests dispersion values around $90 \%$.

\subsection{Continuous gas-flow reactor experiments}

3.2.1 Temperature programmed reaction experiments. The results from the TPReaction experiments with different oxygen concentrations ( $8 \%$ and $1500 \mathrm{ppm})$ for the $\mathrm{Pt} /$ silica, Pt/alumina and Pt/ceria catalysts are shown in Fig. 2a-c, respectively. The Fig. displays the consumption of methane and in the case of $1500 \mathrm{ppm} \mathrm{O}_{2}$ also the consumption of oxygen versus temperature. For both the Pt/silica and $\mathrm{Pt} /$ alumina samples, the methane consumption is negligible below $350^{\circ} \mathrm{C}$. Above this temperature the observed methane consumption is generally higher for the experiments with low oxygen concentration. For the Pt/ceria sample, the methane consumption starts around $300^{\circ} \mathrm{C}$. In contrast to the silica and alumina samples, the methane consumption is higher for the higher oxygen concentration for Pt/ceria. Neither $\mathrm{CO}$ nor $\mathrm{H}_{2}$ could be detected indicating that total oxidation of methane is the dominating reaction under the present experimental conditions. This is further supported by the fact that the consumed amounts of oxygen correspond to the stoichiometric amounts for total oxidation of methane during the entire experiments. As will be shown, this is the case for all experiments in this study. Moreover, a minor reversed hysteresis, i.e., ignition profile positioned at lower temperatures than the corresponding extinction profile, may be seen for the Pt/ceria sample.

The results from the TPReaction experiments with $\mathrm{SO}_{2}$ for $\mathrm{Pt} /$ silica, Pt/alumina and Pt/ceria are shown, in Fig. ??d-i and 3. Fig. 2d-f displays the consumption of methane and oxygen as a function of increasing inlet gas temperature for oxidation of $500 \mathrm{ppm} \mathrm{CH}_{4}$ with $1500 \mathrm{ppm} \mathrm{O}_{2}$ for fresh samples (cycle 3 ), during the addition of $20 \mathrm{ppm} \mathrm{SO}_{2}$ to the feed (cycle 6) and after removal of $\mathrm{SO}_{2}$ from the feed (cycle 9).

It can be seen that the consumption of methane over the fresh $\mathrm{Pt} /$ silica sample starts around $350^{\circ} \mathrm{C}$ by an increase in consumed amount of methane. As soon as $\mathrm{SO}_{2}$ is introduced into the feed an immediate decrease in methane consumption is observed. However, the methane oxidation is completely recovered after removal of $\mathrm{SO}_{2}$ from the feed, ( $c f$. cycle 3 and 9). The fresh Pt/alumina sample shows negligible methane consumption below $350^{\circ} \mathrm{C}$ and a slightly lower $\mathrm{CH}_{4}$ consumption at $500^{\circ} \mathrm{C}$ as compared to the corresponding experiment for the fresh $\mathrm{Pt} /$ silica sample. However, feeding $\mathrm{SO}_{2}$ at $500^{\circ} \mathrm{C}$ results in an increase of the methane consumption (this will be discussed in more detail below) and during both cooling and heating the consumed amounts of methane show a local maximum around $350^{\circ} \mathrm{C}$ and higher consumption of methane at $500^{\circ} \mathrm{C}$. After removal of $\mathrm{SO}_{2}$ from the feed, the methane oxidation declines somewhat, although the consumed amount of methane are still higher than for the fresh sample, and no local consumption maximum is observed. For the fresh $\mathrm{Pt} /$ ceria sample the methane oxidation is negligible below $300^{\circ} \mathrm{C}$. Introducing $\mathrm{SO}_{2}$ to the feed results in an increase of the methane consumption at low temperatures, however, at high temperatures the consumption of methane is considerably lower than for the fresh sample. After removal of $\mathrm{SO}_{2}$ from the feed, the methane oxidation declines even further showing only a minor consumption at $500^{\circ} \mathrm{C}$.

To facilitate the analysis of the promoting effect of sulfur on the methane oxidation, the methane consumption as a function of temperature for successive cooling-heating cycles for oxidation of $500 \mathrm{ppm} \mathrm{CH}_{4}$ with $1500 \mathrm{ppm} \mathrm{O}_{2}$ in the presence of 20 ppm $\mathrm{SO}_{2}$ (cycle 4-6) is displayed in Fig. $2 \mathrm{~g}$-i. The outlet $\mathrm{SO}_{2}$ concentration for these cycles is shown in Fig. 3. For the $\mathrm{Pt} /$ silica sample both the methane consumption and the outlet $\mathrm{SO}_{2}$ concentration during the three cooling-heating cycles overlap and the methane consumption is shifted towards higher temperatures as compared to the previous cycle without $\mathrm{SO}_{2}$. As shown in Fig. 3a, the sulfur dioxide is always present in the product stream below $350^{\circ} \mathrm{C}$ and for temperatures above $400^{\circ} \mathrm{C}$ the thermodynamic equilibrium for $\mathrm{SO}_{2}$ oxidation is approached.

Contrarily, for the Pt/alumina sample, a progressive increase of the methane consumption with time on stream is seen both for the cooling and heating ramp experiments. The maximum methane consumption is observed after the sixth heating ramp. Furthermore, it can be noted that the local consumption maximum between 315 and $390^{\circ} \mathrm{C}$ also increases as a function of time on stream appearing most pronounced for cycle 6 . Only negligible amounts of $\mathrm{SO}_{2}$ can be detected below $250^{\circ} \mathrm{C}$ during the first cooling ramp in presence of sulfur (cycle 4 in Fig. 3b). During the subsequent heating ramp remarkable amounts of $\mathrm{SO}_{2}$ are detected below $350^{\circ} \mathrm{C}$ showing a maximum around $160^{\circ} \mathrm{C}$. A low $\mathrm{SO}_{2}$ signal can be seen also above $450^{\circ} \mathrm{C}$. Large amounts of $\mathrm{SO}_{2}$ below $300^{\circ} \mathrm{C}$ are detected also during cycles 5 and 6 and this $\mathrm{SO}_{2}$ concentration increases with decreasing temperature. The behavior is more complex at the higher temperatures. Depending on whether the tem- 


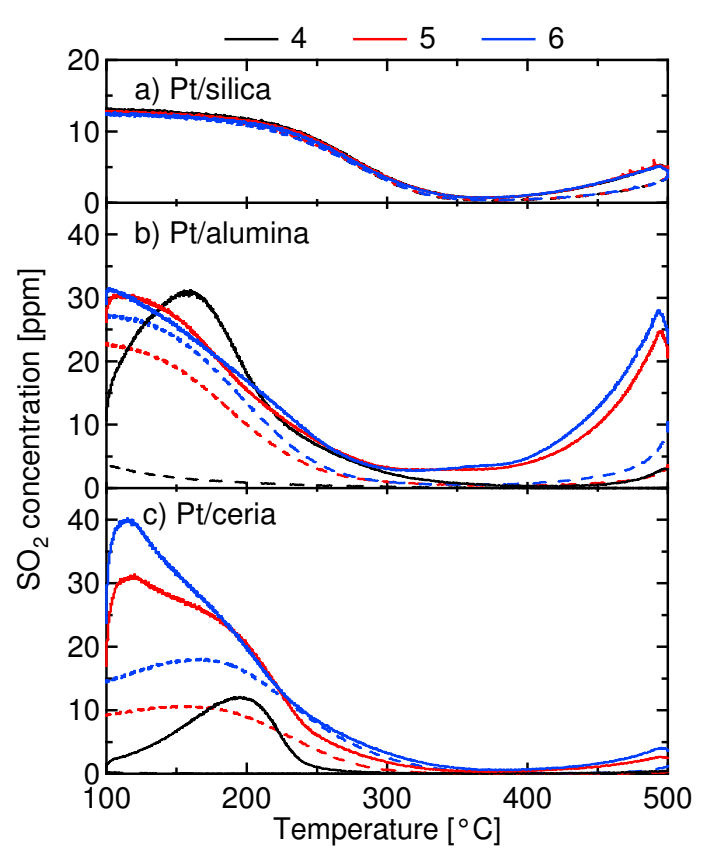

Fig. 3 Outlet $\mathrm{SO}_{2}$ concentration during temperature programmed reaction of $500 \mathrm{ppm} \mathrm{CH}_{4}$ with $1500 \mathrm{ppm} \mathrm{O}_{2}$ in the presence of 20 ppm $\mathrm{SO}_{2}$ over a) $4 \% \mathrm{Pt} /$ silica, b) $4 \% \mathrm{Pt} /$ alumina and c) $4 \% \mathrm{Pt} /$ ceria during cooling (dashed lines) and heating (solid lines). The ramp rate for both cooling and heating is $5^{\circ} \mathrm{C} / \mathrm{min}$ and the GHSV is 15000 $\mathrm{h}^{-1}$. The color code for the consecutive cycle numbers is indicated.

perature is decreased or increased, a pronounced peak of $\mathrm{SO}_{2}$ above $400^{\circ} \mathrm{C}$ is observed. Here the heating ramps result in a maximum at around $495^{\circ} \mathrm{C}$ whereas only minor amounts of $\mathrm{SO}_{2}$ can be detected during the cooling ramps. For the $\mathrm{Pt} /$ ceria sample the introduction of $\mathrm{SO}_{2}$ to the feed gas at $500^{\circ} \mathrm{C}$ results in an instant increase in methane consumption. The profile of the methane consumption during the following cooling ramp (cycle 4) is similar as to cycle 3 (Fig. 2i), although somewhat shifted towards lower temperatures. A considerably stronger shift of the methane consumption towards lower temperatures is seen for the following heating ramp (cycle 4). For the remaining cycles in presence of $\mathrm{SO}_{2}$ (cycles 5 and 6), the methane consumption decreases, primarily during the stationary temperature periods at $500^{\circ} \mathrm{C}$. In contrast to the first three cycles (not shown), a clear extinction-ignition hysteresis is observed between 250 and $500^{\circ} \mathrm{C}$, with higher methane consumption at all temperatures for the heating ramps. Finally, for cycles 7-9 after sulfur exposure the consumption of methane is generally low and negligible below $400^{\circ} \mathrm{C}$ (not shown). In the case of the Pt/ceria sample, $\mathrm{SO}_{2}$ is not detected during the first cooling ramp in presence of sulfur (Fig. 3c). However, for the following heating ramp $\mathrm{SO}_{2}$ is observed below $250^{\circ} \mathrm{C}$ with a maximum around $195^{\circ} \mathrm{C}$. Moving to cycle 5 , some $\mathrm{SO}_{2}$ can be seen below $300^{\circ} \mathrm{C}$ for the cooling ramp and for the heating ramp a net release of $\mathrm{SO}_{2}$ between 100 and $200^{\circ} \mathrm{C}$ with a maximum around $120^{\circ} \mathrm{C}$ can be observed. Negligible amounts of $\mathrm{SO}_{2}$ are seen above $400^{\circ} \mathrm{C}$. The $\mathrm{SO}_{2}$ profiles during cycle 6 show the same trends although in general higher concentrations are observed.

3.2.2 Transient $\mathrm{SO}_{2}$ experiments. The results of the isothermal transient $\mathrm{SO}_{2}$ exposure experiments over $\mathrm{Pt} /$ silica, $\mathrm{Pt} /$ alumina and $\mathrm{Pt} /$ ceria performed at 400 and $500^{\circ} \mathrm{C}$ are shown in 4 . The two top panels show the consumption of methane and oxygen as a function of time while the two bottom panels show the outlet $\mathrm{SO}_{2}$ concentration at 500 and $400^{\circ} \mathrm{C}$, respectively. From Fig. $4 \mathrm{a}$ it is clear that the methane consumption over $\mathrm{Pt} /$ silica at $500^{\circ} \mathrm{C}$ decreases abruptly when $\mathrm{SO}_{2}$ is introduced and then gradually recovers to the initial conversion level during the following sulfur-free period. The concentration of $\mathrm{SO}_{2}$ at the reactor outlet is around $23 \mathrm{ppm}$ for each pulse. At $400^{\circ} \mathrm{C}$, the effects of $\mathrm{SO}_{2}$ on the methane consumption can hardly be discerned due to the low methane conversion. The increased consumption of oxygen in the presence of $\mathrm{SO}_{2}$ indicates oxidation of $\mathrm{SO}_{2}$ into $\mathrm{SO}_{3}$. For Pt/alumina (cf. Fig. 4b) the methane consumption increases in the presence of $\mathrm{SO}_{2}$ for both temperatures investigated and this effect seems to become more pronounced as a function of time on stream. The methane consumption decreases gradually between the $\mathrm{SO}_{2}$ pulses although not to an as low level as at the start of the experiment. This is especially clear at $500^{\circ} \mathrm{C}$, leading to an overall increase of the methane consumption during the time of the experiment. At $400^{\circ} \mathrm{C}$ the concentration of $\mathrm{SO}_{2}$ at the reactor outlet is minor during the entire experiment, whereas at $500^{\circ} \mathrm{C}, \mathrm{SO}_{2}$ is clearly detected between $\mathrm{t}=4-12 \mathrm{~h}$. The detected $\mathrm{SO}_{2}$ is below the feed concentration throughout the experiment. Finally, for Pt/ceria at both temperatures studied, the methane consumption increases in presence of $\mathrm{SO}_{2}$ although this effect becomes less pronounced over the time of the experiment ( $c f$. Fig. $4 \mathrm{c}$ ). At $500^{\circ} \mathrm{C}$, the methane consumption decreases rapidly during the sulfur-free periods leading to an overall deactivation of the catalyst. In contrast, at $400^{\circ} \mathrm{C}$, the increase in $\mathrm{CH}_{4}$ consumption during $\mathrm{SO}_{2}$ pulses is even more pronounced throughout the entire experiment and the decline in overall activity is slower. Furthermore, after the first three pulses, some of the increased methane oxidation remains leading to an overall increase in methane consumption for the first part of the experiment. In both cases $\mathrm{SO}_{2}$ cannot be detected at the reactor outlet.

\subsection{In situ DRIFT spectroscopy measurements}

3.3.1 Transient $\mathrm{SO}_{2}$ exposure experiments. The DRIFTS results during the isothermal transient $\mathrm{SO}_{2}$ exposure experiments over Pt/silica, Pt/alumina and Pt/ceria at 400 and $500^{\circ} \mathrm{C}$ are shown in Fig. 5a-c and Fig. 6a-c, respectively. Fig. 
a) Pt/silica

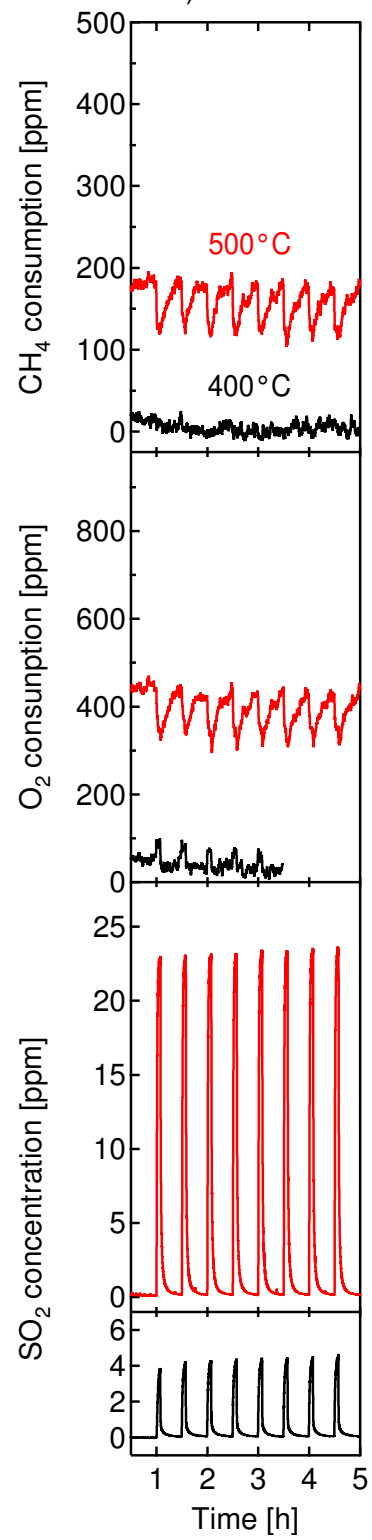

b) Pt/alumina

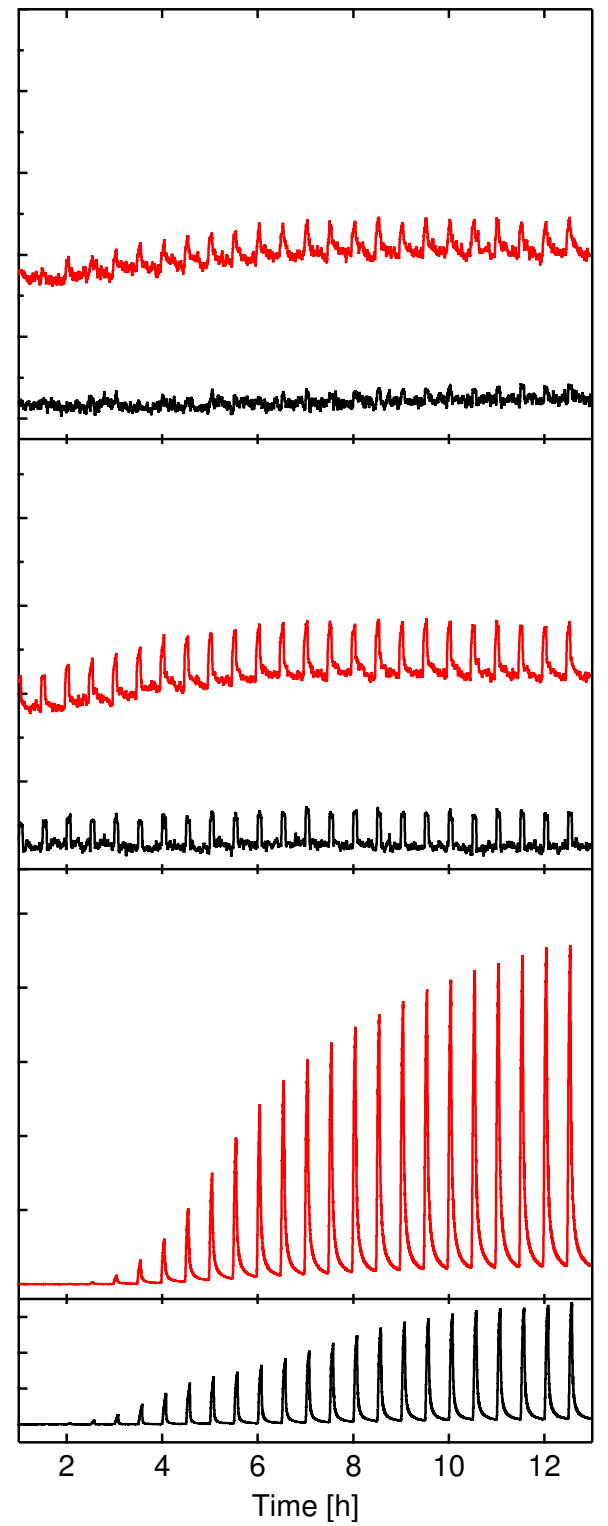

c) Pt/ceria

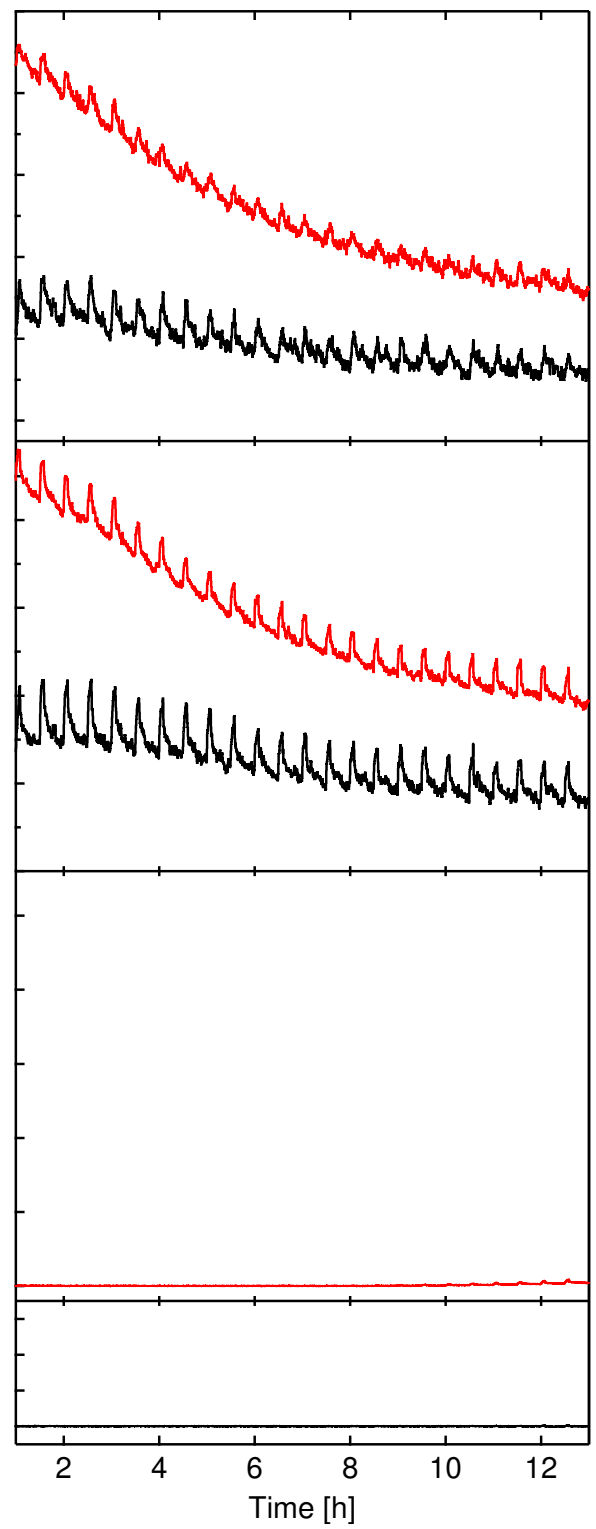

Fig. 4 Transient $\mathrm{SO}_{2}$ exposure experiments (100 $\mathrm{ppm} \mathrm{SO}_{2}$ for $5 \mathrm{~min}$ ) over a) $4 \% \mathrm{Pt} / \mathrm{silica}$, b) $4 \% \mathrm{Pt} /$ alumina and c) $4 \% \mathrm{Pt} / \mathrm{ceria}$ at isothermal conditions at 400 (black lines) and $500^{\circ} \mathrm{C}$ (red lines). The two top panels display the consumption of methane and oxygen as a function of time on stream and the two bottom panels show the corresponding responses in $\mathrm{SO}_{2}$ concentration in the reactor outlet. Continuous feed of $500 \mathrm{ppm} \mathrm{CH}_{4}$ and $1500 \mathrm{ppm} \mathrm{O}_{2}$ in Ar with a GHSV of $15000 \mathrm{~h}^{-1}$. 
5 shows the IR spectra in the interval 1000 to $4000 \mathrm{~cm}^{-1}$ collected for the fresh sample ( $\mathrm{t}=1 \mathrm{~min})$, after the first $(\mathrm{t}=11 \mathrm{~min})$, fourth $(\mathrm{t}=101 \mathrm{~min})$ and fifth $(\mathrm{t}=166 \mathrm{~min}) \mathrm{SO}_{2}$ exposure while Fig. 6 displays the evolution of certain IR bands (integrated peak area) as a function of time, which is described in more detail below. The shaded regions in Fig. 6 represent periods with sulfur present in the feed. Despite the sample dilution with natural diamond nearly complete IR absorption by silica in the region $1000-1200 \mathrm{~cm}^{-1}$ is observed and thus this region is omitted in the forthcoming discussion on Pt/silica. The top panel in Fig. 5a shows the IR spectra collected during the transient $\mathrm{SO}_{2}$ exposure experiment with $\mathrm{Pt} /$ silica at $400^{\circ} \mathrm{C}$. After the first $\mathrm{SO}_{2}$ pulse at $\mathrm{t}=11 \mathrm{~min}$, an absorption band at $1425 \mathrm{~cm}^{-1}$ appears, which is accompanied by two negative absorption bands at 3850 and $3720 \mathrm{~cm}^{-1}$. The first band is characteristic for sulfate species on silica ${ }^{42}$ and the two latter bands origin from isolated hydroxyl groups on silica ${ }^{42-44}$. Moreover, a small positive peak corresponding to the deformation vibration of condensed water is observed at around $1600 \mathrm{~cm}^{-1}$ together with two series of negative sharp rotational bands between $3950-3550 \mathrm{~cm}^{-1}$ and $1800-1400 \mathrm{~cm}^{-1}$, which are characteristic for gaseous water ${ }^{45}$. Only a slight increase of the absorption band related to sulfates on silica is observed after the fourth $(\mathrm{t}=101 \mathrm{~min})$ and fifth pulses $(\mathrm{t}=166$ min). After significant $\mathrm{SO}_{2}$ exposure, a new broad absorption band related to perturbed hydroxyl groups on silica ${ }^{42-44}$ appears around $3320 \mathrm{~cm}^{-1}$ and the bands at 3850 and 3720 $\mathrm{cm}^{-1}$ become even more negative. The corresponding experiment at $500^{\circ} \mathrm{C}$ shows similar results, however, after significant $\mathrm{SO}_{2}$ exposure ( $\mathrm{t}=101$ and $\left.166 \mathrm{~min}\right)$ a new absorption band appears at $1285 \mathrm{~cm}^{-1}$. As this is close to the reported position for the bending mode of $\mathrm{SiS}$ in silicon oxysulfide $(\mathrm{OSiS})^{46}$, it is possible that bulk-like sulfur containing species are formed at $500^{\circ} \mathrm{C}$. However, the corresponding experiments with natural diamond alone show overlapping IR absorption bands and thus the band at $1285 \mathrm{~cm}^{-1}$ is more likely related to the dilutant rather than the bulk-sulfates on silica. Moreover, a positive band appears at $3740 \mathrm{~cm}^{-1}$, which is assigned to isolated hydroxyl groups on silica. For this period the intensity of the hydroxyl bands $\left(3850-3600 \mathrm{~cm}^{-1}\right)$ is nearly constant. The bottom panel in Fig. 6a also shows that the integrated peak area for sulfates on silica $\left(1480-1200 \mathrm{~cm}^{-1}\right)$ increases during $\mathrm{SO}_{2}$ exposure.

Moving to the results for the Pt/alumina sample at $400^{\circ} \mathrm{C}$, absorption bands for gaseous water $\left(3950-3550 \mathrm{~cm}^{-1}\right.$ and $1800-1400 \mathrm{~cm}^{-1}$ ) are observed after $1 \mathrm{~min}$ in the reaction mixture (Fig. 5b, top panel). A tiny positive absorption band at $1585 \mathrm{~cm}^{-1}$, corresponding to the deformation vibration of condensed water ${ }^{21,47-49}$, is also be seen. The appearance of IR absorption bands at 1372 and $1065 \mathrm{~cm}^{-1}$ after the first $\mathrm{SO}_{2}$ pulse at $\mathrm{t}=11 \mathrm{~min}$ indicates the formation of both sulfate $\left(\mathrm{SO}_{4}{ }^{2-}\right)$ and sulfite $\left(\mathrm{SO}_{3}{ }^{2-}\right)$ species, respectively, on the alu-

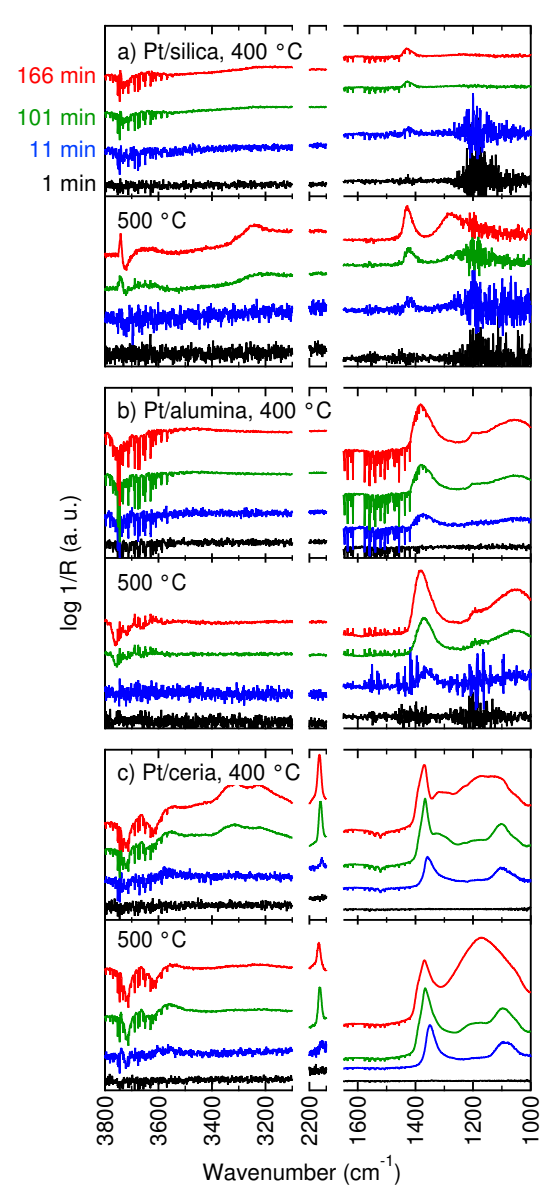

Fig. 5 IR spectra collected on the fresh sample $(t=1 \mathrm{~min})$ and during transient $\mathrm{SO}_{2}$ exposure experiments $\left(40 \mathrm{ppm} \mathrm{SO}_{2}\right)$ after the first $(\mathrm{t}=11 \mathrm{~min})$, fourth $(\mathrm{t}=101 \mathrm{~min})$ and fifth $(\mathrm{t}=166 \mathrm{~min})$ exposure on a) $4 \% \mathrm{Pt} / \mathrm{silica}$, b) $4 \% \mathrm{Pt} /$ alumina and c) $4 \% \mathrm{Pt} /$ ceria at 400 and $500^{\circ} \mathrm{C}$. Continuous feed of $0.05 \% \mathrm{CH}_{4}$ and $0.15 \% \mathrm{O}_{2}$.

mina surface $21,25-27,31,47,50,51$. Two negative absorption bands around 3750 and $3650 \mathrm{~cm}^{-1}$ appear concomitantly. These bands are associated with isolated hydroxyl groups on alumina ${ }^{26,43,47}$. In the spectra collected after the fourth $(t=101$ $\min )$ and the fifth pulses $(t=166 \mathrm{~min})$, an increase in the intensity of the absorption bands associated to superficial sulfates/sulfites can be observed, accompanied by a shift from 1372 to $1381 \mathrm{~cm}^{-1}$ and from 1065 to $1052 \mathrm{~cm}^{-1}$, respectively. The observed shift may be explained either by the combined effect of two overlapping bands that change in relative intensity or by a pure frequency shift of a single band induced by the change in the strength of molecular interactions ${ }^{52}$. Furthermore, a shoulder appears at $1205 \mathrm{~cm}^{-1}$, associated with the formation of bulk-like sulfate species ${ }^{18,26,31,50,51}$. Moreover, the intensity of the IR bands associated to isolated hydroxyl groups becomes more negative with sulfur exposure. 
Considering the results from the transient $\mathrm{SO}_{2}$ exposure experiment at $500^{\circ} \mathrm{C}$ (Fig. $5 \mathrm{~b}$, bottom panel), it can be noticed that the spectrum collected after $1 \mathrm{~min}$ has not changed with respect to the reference spectrum. As in the previous case at $400^{\circ} \mathrm{C}$, the appearance of two absorption bands at 1372 and $1065 \mathrm{~cm}^{-1}$ after the first $\mathrm{SO}_{2}$ pulse $(\mathrm{t}=11 \mathrm{~min})$ indicates the formation of surface sulfates and sulfites. After longer exposure to $\mathrm{SO}_{2}(\mathrm{t}=101-166 \mathrm{~min})$ three negative absorption bands appear around 3760,3715 and $3658 \mathrm{~cm}^{-1}$ related to surface hydroxyl groups together with an absorption band around $1205 \mathrm{~cm}^{-1}$, associated to bulk sulfates in the alumina sample. A contemporary increase of the intensity of the absorption bands associated to superficial sulfates and sulfites can be observed, accompanied by a shift from 1372 to $1383 \mathrm{~cm}^{-1}$ and from 1065 to $1058 \mathrm{~cm}^{-1}$, respectively. The results presented in Fig. 6b show that in both experiments the integrated peak area for the IR bands assigned to sulfates/sulfites (1450-1000 $\mathrm{cm}^{-1}$ ) increases in the presence of $\mathrm{SO}_{2}$ and remains high during the sulfur-free periods, whereas the integrated peak area for the IR bands assigned to isolated hydroxyl groups on alumina (3800-3600 $\mathrm{cm}^{-1}$ ) decreases during $\mathrm{SO}_{2}$ exposure and remains low after sulfur exposure.

The DRIFTS results for the transient $\mathrm{SO}_{2}$ exposure experiments over Pt/ceria are shown in Fig. 5c. The top panel shows the spectra collected at $400^{\circ} \mathrm{C}$. After the first $\mathrm{SO}_{2}$ pulse $(\mathrm{t}=$ $11 \mathrm{~min}$ ) two strong absorption bands at 1360 and $1104 \mathrm{~cm}^{-1}$, a weak absorption band at $1195 \mathrm{~cm}^{-1}$ and a weak negative band at $1520 \mathrm{~cm}^{-1}$ can be distinguished. The band at 1360 $\mathrm{cm}^{-1}$ has often been assigned to surface sulfates ${ }^{20,31,53-55}$, whereas the bands at 1195 and $1104 \mathrm{~cm}^{-1}$ likely are related to bulk-like sulfate species ${ }^{20,31,53,54}$. Finally, the negative IR absorption bands around $1520 \mathrm{~cm}^{-1}$ can be assigned to superficial carbonate and/or carboxylate species ${ }^{20,56-60}$ and indicate decomposition/desorption of such species. Considering the spectra collected after the fourth $(\mathrm{t}=101 \mathrm{~min}) \mathrm{SO}_{2}$ pulse, eight new absorption bands can be distinguished at $3725,3625,3320,2137,1615,1540,1318$ and $1233 \mathrm{~cm}^{-1}$, whereas the band at 1360 and $1195 \mathrm{~cm}^{-1}$ shifts to 1370 and $1175 \mathrm{~cm}^{-1}$, respectively. The bands at 1318 and $1233 \mathrm{~cm}^{-1}$ could be assigned to physisorbed $\mathrm{SO}_{2}{ }^{53}$ and bulk-like sulfates species ${ }^{20,31,55}$, respectively. The negative IR absorption bands at $1540 \mathrm{~cm}^{-1}$ can be assigned to superficial carbonate and/or carboxylate species ${ }^{20,56-60}$. The small positive band at $1615 \mathrm{~cm}^{-1}$ is more difficult to assign. Possibly, this band is related either to bulk carbonate, containing three ceriumoxygen bonds ${ }^{57}$, or to adsorbed water. We mention that absorption at similar wavenumbers have been observed for water adsorbed on alumina ${ }^{21,47-49}$. The positive peak at $2137 \mathrm{~cm}^{-1}$ is likely connected to an electronic transition in Ce(III) ${ }^{56,57}$. The negative bands at 3725 and $3625 \mathrm{~cm}^{-1}$ can be related to isolated hydroxyl groups and the positive bands around 3220 and $3300 \mathrm{~cm}^{-1}$ can be assigned to perturbed hydroxyl groups
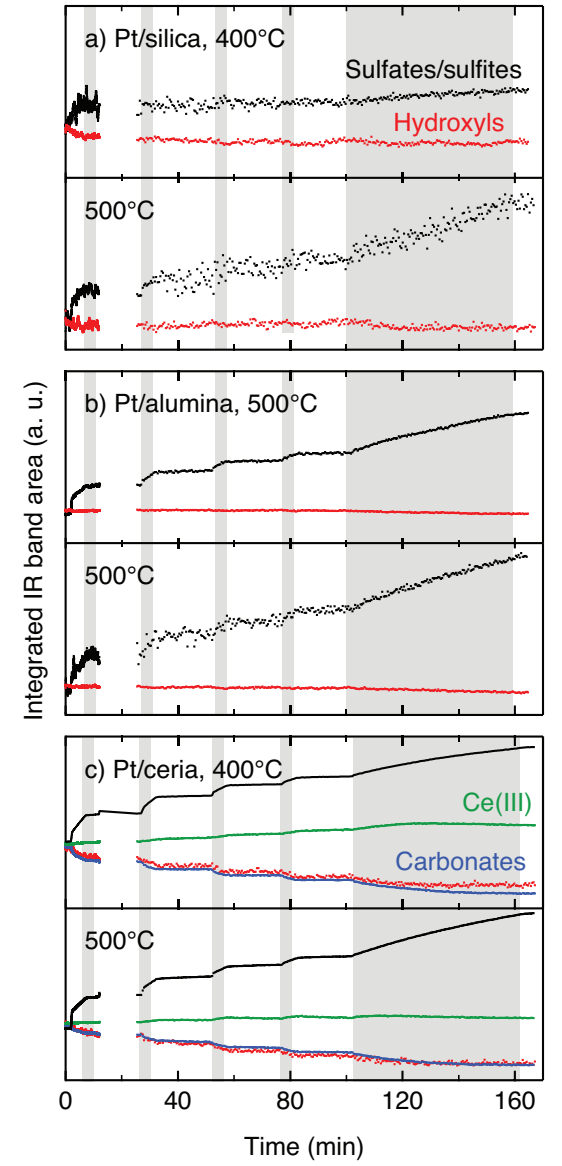

Fig. 6 Integrated peak area for sulfate/sulfite (black) and hydroxyl (red) surface species during transient $\mathrm{SO}_{2}$ exposure experiments on a) $4 \% \mathrm{Pt} /$ silica, b) $4 \% \mathrm{Pt} /$ alumina and c) $4 \% \mathrm{Pt} /$ ceria performed at 400 and $500^{\circ} \mathrm{C}$. For Pt/ceria the integrated peak area for the electronic transition of $\mathrm{Ce}$ (III) (green) and carbonate species (blue) are also reported. The shaded areas represent the periods with $\mathrm{SO}_{2}$ present in the feed.

on ceria ${ }^{53,56,61}$, respectively. After the fifth $\mathrm{SO}_{2}$ pulse $(\mathrm{t}=$ $166 \mathrm{~min}$ ) the intensity of the absorption band at $1370 \mathrm{~cm}^{-1}$ (surface sulfates) remains constant, whereas the peaks associated to physisorbed $\mathrm{SO}_{2}\left(1318 \mathrm{~cm}^{-1}\right)$ and bulk-like sulfates $\left(1233,1175\right.$ and $\left.1104 \mathrm{~cm}^{-1}\right)$ increase and a new peak appears at $1285 \mathrm{~cm}^{-1}$ that we tentatively assign to a different bulklike sulfate species. It is evident from Fig. 6c (top panel) that, as a function of time on stream with sulfur exposure, the integrated area related to sulfur derived species (1420-1000 $\mathrm{cm}^{-1}$ ) increases, together with the band connected to Ce(III) (2200-2060 $\left.\mathrm{cm}^{-1}\right)$. At the same time, the concentration of surface carbonate/carboxylate species $\left(1600-1430 \mathrm{~cm}^{-1}\right)$ decreases and the negative bands associated to hydroxyl species (3850-3560 $\mathrm{cm}^{-1}$ ) become more negative in presence of $\mathrm{SO}_{2}$. 

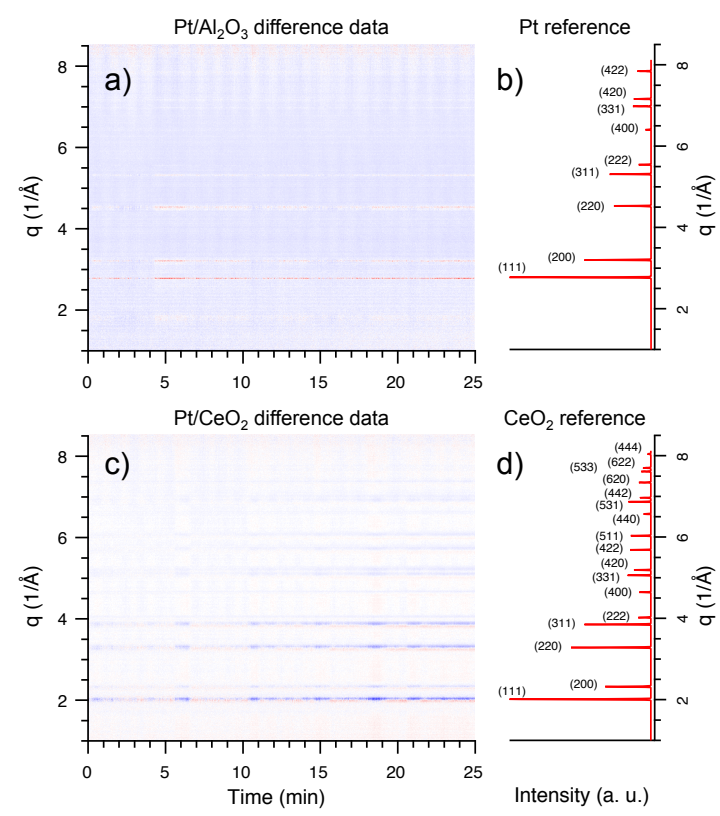

Fig. 7 Time-resolved HE-XRD patterns obtained in situ during oxidation of $1000 \mathrm{ppm}$ methane with $1.5 \% \mathrm{O}_{2}$ at $350^{\circ} \mathrm{C}$ over $\mathrm{Pt} /$ alumina and $\mathrm{Pt} /$ ceria while transiently exposing the samples to $0.05 \% \mathrm{SO}_{2}$ for a duration of $75 \mathrm{~s}$ separated with an equally long period without $\mathrm{SO}_{2}$. Panel a) and c) show color maps for the difference data, i.e., subtraction of the average of the initial ten diffractograms, for the $4 \% \mathrm{Pt} /$ alumina and $4 \% \mathrm{Pt} /$ ceria samples, respectively. Panel b) and d) display the reference diffraction patterns for $\mathrm{Pt}$ and $\mathrm{CeO}_{2}$.

The IR spectra collected at $500^{\circ} \mathrm{C}$ during the transient $\mathrm{SO}_{2}$ exposure experiment for the Pt/ceria sample (Fig. 5, bottom panel) generally shows similar absorption bands as already observed at $400^{\circ} \mathrm{C}$. However, the absorption in the region associated with carbonate/carboxylate differs, with no bands at $500^{\circ} \mathrm{C}$. Moreover, some of the absorption bands detected in the sulfate/sulfite region at $400^{\circ} \mathrm{C}$ are not present at $500^{\circ} \mathrm{C}$, i.e. peaks at 1318,1285 and $1233 \mathrm{~cm}^{-1}$. Furthermore, there are important differences in the relative intensity of the peaks associated to sulfate species and Ce(III). The bands connected to bulk sulfates (1175 and $1104 \mathrm{~cm}^{-1}$ ) are much more pronounced and the peak around $2137 \mathrm{~cm}^{-1}$ is less intense at $500^{\circ} \mathrm{C}$. Again the integrated area for the sulfur derived species $\left(1420-1000 \mathrm{~cm}^{-1}\right)$ increases in presence of $\mathrm{SO}_{2}$ and remains constant during the following sulfur-free periods.

\subsection{In situ HE-XRD measurements}

The results from the isothermal transient $\mathrm{SO}_{2}$ exposure experiments over the Pt/alumina and $\mathrm{Pt} /$ ceria samples at $350^{\circ} \mathrm{C}$ studied in situ by HE-XRD are shown in Fig. 7. The panels a) and c) present the difference data, i.e. subtraction of the average of the ten initial diffractograms, as color maps with $q$ $(1 / \AA)$ and time on the vertical and horizontal axis, respectively. The intensity is color coded where blue and red represents decreased and increased intensity relative the initial condition, respectively. A change from blue to red at a certain constant $q$ value thus corresponds to an increasing intensity of a certain diffraction line whereas if the change also is accompanied by a change in $q$, a shift of the diffraction line in the blue-to-red direction occurs. Panel b) and d) show reference diffractograms for Pt and ceria, respectively.

Starting with the Pt/alumina sample, the structural changes that can be observed are mainly related to changes of the $\mathrm{Pt}$ particles. However, the changes are minor and only a slight increase in the intensity for $\mathrm{Pt}(111)$ may be discerned as a function of $\mathrm{SO}_{2}$ exposure. It is not straightforward to determine the significance of this change. However, it is clear that no major structural changes occur during $\mathrm{SO}_{2}$ promoted methane oxidation. Moving to the Pt/ceria system, the majority of the observed diffraction lines originate from ceria. In a more detailed analysis of the diffractograms a weak line from $\operatorname{Pt}(111)$ can be discerned, however, this is considerably weaker than, e.g., the (111), (200), (220) and (311) diffraction lines for ceria. In contrast to $\mathrm{Pt} /$ alumina, the main changes in the $\mathrm{Pt} /$ ceria sample occurs in the support phase ( $c f$. panel c)). The (111), (200), (220) and (311) diffraction lines shift towards lower $q$ values (blue-to-red direction), which reflects an expansion of the lattice parameter during the $\mathrm{SO}_{2}$ exposure experiment. The changes in $q$ correspond to a relative expansion of the lattice parameters of about 2-3\%.

\section{Discussion}

In the presented work we have studied sulfur promoted methane oxidation over different model catalysts. Before discussing the kinetics results we make a few comment on the physical characterisation of the catalysts. The STEM analysis clearly show that for all three samples the majority of the Pt particles are below three $\mathrm{nm}$ in diameter (cf. Fig. 1). Thus the vast majority of the Pt particles are sufficiently small to be susceptible towards electronic modifications by the support ${ }^{62-64}$, strong metal-support interactions (SMSI), and edge effects by atoms in contact with the support facilitating spillover of species between the metal particles and the support. The present model catalysts can therefore, in this respect, be considered representative of real industrial catalysts where all the mentioned processes are important for the catalytic properties.

The present results from TPReaction experiments with different oxygen concentrations (Fig. 2a-c) agree well with previous studies showing that the activity for methane oxidation over $\mathrm{Pt} / \mathrm{Al}_{2} \mathrm{O}_{3}$ strongly depends on the feed gas composition ${ }^{12-15}$. In addition, the TPReaction experiments show 
that the influence of the oxygen concentration on the oxidation of methane in excess oxygen is different for silica, alumina and ceria supported platinum. At the high oxygen concentration, the methane oxidation is suppressed for Pt/silica and Pt/alumina whereas for Pt/ceria the activity increases. In all experiments, the dominating process is total oxidation of methane. This is evidenced by the fact that neither formation of $\mathrm{CO}$ nor $\mathrm{H}_{2}$ could be observed in any experiment. Further, analysis of the oxygen balance shows that the consumed amount of oxygen well matches the expected consumption for stoichiometric total oxidation of methane. Thus the results for $\mathrm{Pt} /$ ceria are hardly biased by incomplete oxidation of ceria at the start of the experiment, which principally could be the case and lead to experimental artifacts as a significant amount of the supplied oxygen then would be stored in the ceria support rather than used for oxidation of methane. Based on this we can reason as follows. Accepting that the main reaction path for methane oxidation on $\mathrm{Pt}$ is dominated by the LangmuirHinshelwood (LH) type of mechanism involving reaction between dissociated methane and oxygen species ${ }^{12-15}$. The inhibiting effect of oxygen observed over both Pt/silica and Pt/alumina can then be explained by a site competition between oxygen and methane ${ }^{1,15}$ favoring the adsorption of oxygen due to the considerably higher sticking probability of oxygen on platinum as compared to methane ${ }^{65,66}$. The stronger oxygen poisoning for $\mathrm{Pt} / \mathrm{silica}$ may result from that oxygen cannot spill over to silica, not even oxygen adsorbed on sites located at the Pt-silica boundary as the Pt particles interact weakly with silica, effectively leading to a higher oxygen coverage/oxide formation on Pt. Contrarily, for Pt/alumina, the stronger interactions between the Pt particles and alumina may introduce more active sites at the Pt-alumina boundary such that these sites are less susceptible towards oxygen selfpoisoning/oxide formation.

Contrasting the results for the Pt/ceria sample with those for $\mathrm{Pt} /$ silica and $\mathrm{Pt} /$ alumina, the $\mathrm{Pt} /$ ceria system exhibits significantly stronger metal support interactions ${ }^{67}$ that may modify platinum sites. Especially, sites close to the noble metalsupport interface that are more active for methane dissociation or activation of reactive oxygen atoms. The latter is for example supported by the results by Tang et al. ${ }^{68}$, who observed that doping the $\mathrm{CeO}_{2}$ surface with $\mathrm{Pt}$ weakened the bond strength to neighboring oxygen in the oxide, resulting in oxygen species more reactive for methane oxidation. Besides, the importance of active sites on the ceria surface should also be considered ${ }^{20}$. Thus we propose that dissociated oxygen species on platinum can either react with dissociated methane species on Pt or diffuse towards ceria and react on sites at the noble metal-support interface ${ }^{69}$, or spill over and possibly react with dissociated methane on ceria ${ }^{60}$. The latter may occur via either a LH mechanism involving activated oxygen species or via a Mars van Krevelen type of mechanism involving lat- tice oxygen. Accepting the latter, the observed increased activity for methane oxidation with increased oxygen concentration could be explained by an enhancement of both oxygen surface transport and ceria (re)oxidation with increasing oxygen concentration.

The choice of support material for Pt clearly plays an important role in the promotion of the low-temperature oxidation of methane. The remaining discussion will focus on the effect of sulfur on the oxidation of methane over the three different Pt-support systems. Due to the low activity for methane oxidation at high oxygen concentration (8\%) for the Pt/silica and $\mathrm{Pt} /$ alumina samples, the lower concentration of $1500 \mathrm{ppm} \mathrm{\textrm {O } _ { 2 }}$ was used for the sulfur experiments to ensure a proper analysis of the promoting and inhibiting effects of sulfur for all samples. As in this connection methane oxidation is considerably less studied compared to for example oxidation of propane, we will make appropriate analogies with sulfur promoted propane oxidation in the following discussion.

It is well known that silica has low affinity towards acidic compounds like $\mathrm{SO}_{2}$ and $\mathrm{NO}^{70,71}$, i.e. neither sulfite/sulfate nor nitrite/nitrate species are formed to significant extents on the Pt/silica system $22,25,72$. This is demonstrated in the transient $\mathrm{SO}_{2}$ exposure experiment (Fig. 4) for which the transient supply of $\mathrm{SO}_{2}$ results in rapid breakthrough of $\mathrm{SO}_{2}$, reflecting low sulfur storage on the sample. Further evidences can be found in the DRIFTS experiments ( $c f$. Fig. 6a), which show that saturation of sulfates/sulfites is readily reached during $\mathrm{SO}_{2}$ exposure at $400^{\circ} \mathrm{C}$ (some interactions, which will be treated towards the end of the discussion, can however be discerned). For this reason, the observed conversion of methane over the Pt/silica sample reaches the same level before and after $\mathrm{SO}_{2}$ exposure (Fig. 2g-i), which is in line with previous studies on propane oxidation ${ }^{22,23,25,73}$. However, in contrast to propane oxidation, a clear inhibition of the methane oxidation can be observed in presence of $\mathrm{SO}_{2}$. This is especially clear in the transient $\mathrm{SO}_{2}$ exposure experiments (Fig. 4) where the activity significantly drops during each period with $\mathrm{SO}_{2}$ and recovers thereafter. The detected outlet level of $\mathrm{SO}_{2}$ is however significantly lower than the feed concentration, which is due to oxidation of $\mathrm{SO}_{2}$ into $\mathrm{SO}_{3}$ as demonstrated by the oxygen balance. The oxidation of $\mathrm{SO}_{2}$ is further supported by the TPReaction experiment (Fig. 3) showing an onset of the oxidation of $\mathrm{SO}_{2}$ around $200^{\circ} \mathrm{C}$, which becomes significant around $300^{\circ} \mathrm{C}$. At the highest temperatures, the detected amount of $\mathrm{SO}_{2}$ corresponds to the $\mathrm{SO}_{2} / \mathrm{SO}_{3}$ equilibrium concentration. Furthermore, a detailed analysis of the consumed amount of oxygen shows that slightly more oxygen than would have been used for stoichiometric total oxidation of methane is consumed, which is indicative of $\mathrm{SO}_{2}$ oxidation by dissociated oxygen on platinum. Considering these observations, the drop in methane conversion during $\mathrm{SO}_{2}$ exposure is due to competition between $\mathrm{SO}_{2}$ and $\mathrm{CH}_{4}$ adsorption favor- 
ing $\mathrm{SO}_{2}$ adsorption due to the higher sticking probability of $\mathrm{SO}_{2}$ on platinum as compared to $\mathrm{CH}_{4}{ }^{69,74}$. The different response to $\mathrm{SO}_{2}$ for methane and propane oxidation over silica supported Pt can be explained by the more even competition between $\mathrm{SO}_{2}$ and propane than for $\mathrm{SO}_{2}$ and methane. In the case of propane this leads to lower inhibiting effect of $\mathrm{SO}_{2}$ on propane oxidation. Besides, Burch et al. ${ }^{23}$ proposed as part of the explanation for $\mathrm{SO}_{2}$ promoted propane oxidation that $\mathrm{SO}_{2}$ oxidation on platinum results in (partial) removal of oxygen from the platinum surface, which leads to an increase in the activity for propane oxidation. However, no promotion by sulfur on propane oxidation on Pt/silica was observed. Our results show that methane oxidation over $\mathrm{Pt} /$ silica is inhibited in the presence of $\mathrm{SO}_{2}$, despite the occurrence of $\mathrm{SO}_{2}$ oxidation. It is thus unlikely that removal of chemisorbed oxygen and/or oxide on Pt through $\mathrm{SO}_{2}$ oxidation enhances the oxidation of hydrocarbons. At least, it seems insufficient at the present experimental conditions.

Unlike for Pt/silica, a significant enhancement of methane oxidation over the Pt/alumina sample in presence of $\mathrm{SO}_{2}$ can be observed both as a low-temperature maximum and a general increase of the methane conversion during the TPReaction experiments (Fig. 2d-i), and as an initial and generally increasing methane conversion during the transient $\mathrm{SO}_{2}$ exposure experiments. In the TPReaction experiment, the promoting effect increases for each cycle with $\mathrm{SO}_{2}$ (Fig. 2g-i) and remains, at least partially, even after the sulfur exposure periods (Fig. 2d-f). The present results are in line with the observations by Dupont et al. ${ }^{17}$ and Corro et al. ${ }^{18}$, who observed a promotional effect of $\mathrm{SO}_{2}$ on the oxidation of methane over $\mathrm{Pt}$ /alumina. Moreover it corresponds well with the analogous sulfur promoted propane oxidation over $\mathrm{Pt} / \mathrm{Al}_{2} \mathrm{O}_{3}$, which has been studied more extensively ${ }^{22-27}$. In the case of propane oxidation different explanations have been proposed for the promoting effect of $\mathrm{SO}_{2}$. Among them, the formation of new active sites that more effectively can break the $\mathrm{C}-\mathrm{H}$ bond via dissociation seems most likely. Such active sites are proposed to be composed by adjacent cationic $\left(\mathrm{Pt}^{\delta+}\right)$ and anionic $\left(\mathrm{SO}_{4}^{2-}\right)$ moieties at the noble metal-support interface ${ }^{23}$. From the detected outlet concentration of $\mathrm{SO}_{2}$ (Fig. 3) it is clear that much $\mathrm{SO}_{2}$ is stored during the first cycle and for the remaining cycles with $\mathrm{SO}_{2}$ the system is, at least partly, regenerated. The observed minimum in outlet $\mathrm{SO}_{2}$ concentration between 300 and $400^{\circ} \mathrm{C}$ is due to both formation of sulfates on alumina and the equilibrated $\mathrm{SO}_{2}$ oxidation described above. As for $\mathrm{Pt} /$ silica, the detailed analysis of the amount of consumed oxygen indicates significant $\mathrm{SO}_{2}$ oxidation by gas phase oxygen also for Pt/alumina. The formation of sulfates likely involves formation also of interfacial sulfates $\left(\mathrm{Al}_{2}\left(\mathrm{SO}_{4}\right)_{3}\right)$ through a platinum catalyzed reaction between the adsorbed $\mathrm{SO}_{3}$ and $\mathrm{Al}_{2} \mathrm{O}_{3}{ }^{27}$. These interfacial sulfates can provide sites highly active for methane dissociation. Thus the general trend of in- creasing methane conversion as a function of time on stream observed here may be a result of successive formation of these interfacial sites and the observed methane conversion at low temperature (the maximum) is a result of methane dissociation via these sites. The reason for the maximum and not a successively increasing methane conversion can be due to decomposition of interfacial sulfates and subsequent desorption of $\mathrm{SO}_{x}{ }^{25}$ (Fig. 3) and possibly also migration of ad-SO $\mathrm{S}_{x}$ species from interfacial locations to the support resulting in a decrease of the number of highly active sites. The latter is supported by the DRIFTS results showing that the amount of sulfate species (integrated area) is constant during sulfur-free periods. Furthermore, the DRIFTS results provide new evidences for the formation of superficial sulfates (Fig. 5b), which may be responsible for the improved catalytic activity. The HE-XRD results show no evidences for formation of alumina bulk sulfates, at least not with an ordered structure, and thus sulfation of alumina is likely to involve only the surface region of the support. The transient $\mathrm{SO}_{2}$ exposure experiment further supports that the sample needs to be sufficiently sulfated to show a promoting effect on the methane oxidation. At the start of this experiment a negligible promotional effect is observed while all supplied sulfur is stored. After a few $\mathrm{SO}_{2}$ exposure periods the promoting effect becomes more and more clear. This is accompanied by an increasing $\mathrm{SO}_{2}$ breakthrough for each $\mathrm{SO}_{2}$ period, which is due to that the supplied sulfur gradually is stored to a lesser extent while $\mathrm{SO}_{2}$ oxidation remains. The latter is supported by the fact that the detected $\mathrm{SO}_{2}$ concentration is lower than the supplied concentration.

In comparison with $\mathrm{Pt} /$ silica and $\mathrm{Pt} /$ alumina, the behavior of the $\mathrm{Pt} /$ ceria sample is more complex as $\mathrm{SO}_{2}$ exposure impose both promoting and inhibiting effects on the methane oxidation. The present results, which are based on considerably lower oxygen concentration, agree well with the recent results by Kylhammar et al. ${ }^{20}$. Generally a promoting effect has been observed during the heating ramps in presence of $\mathrm{SO}_{2}$ in the TPReaction experiments and the periods with $\mathrm{SO}_{2}$ present in the transient $\mathrm{SO}_{2}$ exposure experiments. However, the promoting effect diminishes as a function of time on stream and the methane oxidation becomes inhibited. As mentioned in the Introduction the promoting effect has been discussed in terms of both breakage of oxygen self-poisoning/decomposition of platinum oxides (this is discussed more in next paragraph), electronic modification of platinum sites and/or formation of new highly active sites in the noble metal-support interface upon sulfate formation. The present results strongly support the latter, i.e., formation of $\mathrm{Pt}^{\delta+} / \mathrm{SO}_{4}^{2-}$ pairs acting as highly active sites for methane dissociation as the main cause for the promotional effect, analogous to Pt/alumina discussed above. The hysteresis in the extinction-ignition cycles is most likely due to that $\mathrm{Pt}$ facilitates formation of interfacial sulfates at low temperature, for example it has been observed that $\mathrm{Pt}$ 
is of significant importance for sulfate formation on ceria at $250{ }^{\circ} \mathrm{C}^{50,75}$ but not at $400^{\circ} \mathrm{C}^{54}$, whereas at higher temperatures sulfate formation occurs directly on the entire ceria surface. Also sulfates formed at the noble metal-support interface may migrate to occupy more stable sulfate configurations on/in the ceria support at high temperature. The observed shifts of the ceria lines towards lower $q$ values in HE-XRD difference color maps provide evidence for a ceria lattice expansion. This in turn indicates a reduction of the ceria support ${ }^{76-78}$, which is intimately connected with the formation of bulk-like sulfates as observed with DRIFTS. Thus, we propose that at $500^{\circ} \mathrm{C}$ sulfates form readily all over the ceria surface with some migration into the surface region, so that at the start of the extinction experiment minor amounts of interfacial sulfates are present and thus the promoting effect is negligible. In the case of possible active sites on the ceria surface as such, these sites may be blocked by the presence of superficial sulfates. On the contrary, at low temperature the main path towards ceria sulfation is via platinum and thus adsorbed sulfur oxides may accumulate preferentially at the Pt-ceria interface and then transform into interfacial sulfates during the heating ramp. Therefore, the enhancement in methane oxidation observed during the ignition experiment is most likely caused by formation of new active sites in the platinum-ceria interface.

The observed extinction-ignition hysteresis may result from ceria reduction-oxidation processes during the experiments. Sulfation of ceria in presence of $\mathrm{SO}_{2}$ and $\mathrm{O}_{2}$ is often coupled with the reduction of cerium from $\mathrm{Ce}(\mathrm{IV})$ to $\mathrm{Ce}(\mathrm{III})^{79}$. This is considered more as a dynamic process, which is operative as long as oxygen is consumed in the sulfate formation process, and could thus explain the diminishing promotion over time. The hysteresis may thus be related to ceria (re-)oxidation as this process likely proceeds via different mechanisms at different temperatures. It is generally accepted that ceria can be oxidized by oxygen from the gas phase at high temperatures, whereas at low temperatures oxidation via oxygen spillover from $\mathrm{Pt}$ is the main route ${ }^{60,69}$. Thus during ignition, the onset of oxygen spillover upon sulfate formation can in principle induce an increase of the number of available platinum sites for methane dissociation by breakage of oxygen selfpoisoning and/or platinum oxides as discussed previously ${ }^{20}$. However, a detailed analysis of the measured oxygen concentration indicates that all consumed oxygen is used for total oxidation of methane and not for oxidation of $\mathrm{SO}_{2}$. This implies that a significant part of the sulfate formation involves lattice oxygen present in the ceria structure rather than dissociated gas phase oxygen. This is supported by the HE-XRD results, i.e., the shifting of the ceria diffraction lines towards lower $q$ values, as discussed above. Thus breakage of oxygen selfpoisoning and/or platinum oxides is expected to play a minor role in this case. Further, the gradient in sulfate concentration between the surface and bulk of ceria may act as the driving force for diffusion of sulfates into the bulk ${ }^{50}$, associated with a corresponding diffusion of oxygen from the bulk to the surface of the ceria support resulting in oxidation of ceria sites ${ }^{56}$. Again, this is supported by the in situ DRIFTS and in situ HEXRD results. The occurrence of bulk diffusion phenomena during the heating process, accompanied by partial ceria (re)oxidation, is therefore demonstrated, so explaining the lower extent of ceria reduction at $500^{\circ} \mathrm{C}$. Finally, the deactivation of the catalyst after sulfur exposure can be explained by a progressive saturation of the ceria support by sulfates, eventually blocking both active sites on ceria and oxygen mobility in the $\mathrm{Pt} /$ ceria system.

\section{Concluding remarks}

The present study shows that by comparing results from platinum catalysts with different support materials, the mechanisms behind $\mathrm{SO}_{2}$ promoted methane oxidation can be clarified. The study also shows that the results for the different systems should, in many respects, be treated separately as each system also exhibits distinct unique properties that govern different surface processes, in the case of ceria even bulk processes, influencing the methane oxidation. This is especially evident in the presence of sulfur, as both promoting and/or inhibiting effects are observed for the different catalysts. Moreover, the spectroscopic data, show that $\mathrm{SO}_{2} / \mathrm{SO}_{3}$ interact differently with the isolated surface hydroxyl groups depending on the type of support. Exposing Pt/silica and Pt/alumina to $\mathrm{SO}_{2}$ leads primarily to a removal of isolated hydroxyl groups except for $\mathrm{Pt} /$ silica at $500^{\circ} \mathrm{C}$ where removal is accompanied by a rearrangement/blockage of hydroxyl groups. Contrarily, for Pt/ceria, blockage of isolated hydroxyl groups evidenced by the formation of perturbed hydroxyl species is clearly seen while removal cannot be excluded. Nevertheless, the interaction between $\mathrm{SO}_{2} / \mathrm{SO}_{3}$ and surface hydroxyl groups is likely a first step in the formation mechanism of ad-SO $\mathrm{S}_{x}$ species, which is shown to promote the low-temperature oxidation of methane by forming new active sites at the noble metalsupport interface. We consider this to be the main cause for the promotional effects while reduction of oxygen poisoning and/or oxide formation on the platinum particles through $\mathrm{SO}_{2}$ oxidation is playing a minor role.

Acknowledgement This study has been performed at the Competence Centre for Catalysis, which is financially supported by Chalmers University of Technology, the Swedish Energy Agency and the member companies: AB Volvo, Volvo Car Corporation, Scania CV AB, Haldor Topsøe A/S and ECAPS AB. Parts of the work have been performed within the InGAS project which is financially supported by the European Commission, FP7 Programme (Proj. no. 218447). The authors gratefully acknowledge the funding from the Knut and Alice Wallenberg Foundation and the Swedish Research 
Council for the advanced transmission electron microscopes and for financial project support (Dnr KAW 2005.0055 and Proj. no. 621-2008-3229). The authors thank the European Synchrotron Radiation Facility (ESRF), Grenoble, France, for providing the beamtime.

\section{References}

1 R. Burch and M. J. Hayes, J. Mol. Catal. A Chem., 1995, 100, 13-33.

2 P. Gélin and M. Primet, Appl. Catal. B Environ., 2002, 39, 1-37.

3 S. H. Oh, P. J. Mitchell and R. M. Siewert, J. Catal., 1981, 132, 287-301.

4 R. Burch and P. K. Loader, Appl. Catal. B Environ., 1994, 5, 149-164.

5 P. Gélin, L. Urfels, M. Primet and E. Tena, Catal. Today, 2003, 83, 45-57.

6 J. K. Lampert, M. S. Kazi and R. J. Farrauto, Appl. Catal. B Environ., 1997, 14, 211-223.

7 R. Burch, P. K. Loader and F. J. Urbano, Catal. Today, 1996, 27, 243-248.

8 F. H. Ribeiro, M. Chow and R. A. Dallabetta, J. Catal., 1994, 146, 537544.

9 C. F. Cullis, T. G. Nevell and D. L. Trimm, J. Che. Soc. Farad. Trans., 1972, 1(68), 1406-1412.

10 R. Burch and P. K. Loader, Appl. Catal. A: Gen., 1995, 122, 169-190.

11 V. P. Zhdanov, P.-A. Carlsson and B. Kasemo, J. Chem. Phys., 2007, 126, 234707.

12 E. Becker, P.-A. Carlsson, H. Grönbeck and M. Skoglundh, J. Catal., 2007, 252, 11.

13 E. Becker, P.-A. Carlsson, L. Kylhammar, M. A. Newton and M. Skoglundh, J. Phys. Chem. C, 2011, 115, 944-951.

14 P.-A. Carlsson, E. Fridell and M. Skoglundh, Catal. Lett., 2007, 115, 1.

15 P.-A. Carlsson, M. Nordström and M. Skoglundh, Top. Catal., 2009, 52, 1962.

16 E. Becker, P.-A. Carlsson and M. Skoglundh, Top. Catal., 2009, 52, 1957.

17 V. Dupont, J. M. Jones, S. H. Zhang, A. Westwood and M. V. Twigg, Chem. Eng. Sci., 2004, 59, 17-29.

18 G. Corro, C. Cano and J. L. G. Fierro, Catal. Comm., 2008, 9, 2601-2605.

19 G. Corro, J. Mol. Catal. A Chem., 2010, 315, 35-42.

20 L. Kylhammar, P.-A. Carlsson and M. Skoglundh, J. Catal., 2011, 284, $50-59$.

21 H. C. Yao, H. K. Stepien and H. S. Gandhi, J. Catal., 1981, 67, 231-236.

22 C. P. Hubbard, K. Otto, H. S. Gandhi and K. Y. S. Ng, J. Catal., 1993, 144, 484-494.

23 R. Burch, E. Halpin, M. Hayes, K. Ruth and J. A. Sullivan, Appl. Catal. B Environ., 1998, 19, 199-207.

24 A. F. Lee, K. Wilson, R. M. Lambert, C. P. Hubbard, R. G. Hurley, R. W. McCabe and H. S. Gandhi, J. Catal., 1999, 184, 491-498.

25 M. Skoglundh, A. Ljungqvist, M. Petersson, E. Fridell, N. Cruise, O. Augustsson and E. Jobson, Appl. Catal. B Environ., 2001, 30, 315-328.

26 A. Hinz, M. Skoglundh, E. Fridell and A. Andersson, J. Catal., 2001, 201, 247-257.

27 G. Corro, R. Montiel and C. L. Vazquez, Catal. Comm., 2002, 3, 533-539.

28 G. Corro, Catal. Comm., 2003, 4, 371-376.

29 L. Zhang, D. Weng, B. Wang and X. Wu, Catal. Comm., 2010, 11, 1229 1232.

30 K. Wilson, C. Hardacre and R. M. Lambert, J. Phys. Chem., 1995, 99, 13755-13758.

31 L. Kylhammar, P.-A. Carlsson, H. H. Ingelsten, H. Grönbeck and M. Skoglundh, Appl. Catal. B: Environ., 2008, 84, 268-276.

32 L. J. Hoyos, H. Praliaud and M. Primet, Appl. Catal. A: General, 1993, 98, 125-138.

33 D. Baurecht and P. Fringeli, Rev. Sci. Inst., 2001, 72, 3782-3792.

34 D. Ferri, M. S. Kumar, R. Wirz, A. Eyssler, O. Korsak, P. Hug, A. Wei- denkaff and M. A. Newton, Phys. Chem. Chem. Phys., 2010, 12, 5634 5646.

35 D. Ferri, M. A. Newton and M. Nachtegaal, Top. Catal., 2011, 54, 10701078.

36 A. Urakawa, T. Büurgi and A. Baiker, Chem. Eng. Sci., 2008, 63, 4902 4909.

37 J. P. Brunelle, Pure Appl. Chem., 1978, 50, 211-232.

38 C. Wang-Hansen, C. J. Kamp, M. Skoglundh, B. Andersson and P.-A. Carlsson, J. Phys. Chem. C., 2011, 115, 16098-16108301.

39 M. A. Newton, Top. Catal., 2009, 52, 1410-1424.

40 M. A. Newton and W. van Beek, Chem. Soc. Rev., 2010, 39, 4845-4863.

41 A. Borodziński and M. Bonarowska, Langmuir, 1997, 13, 5613-5620.

42 B. G. Anderson, Z. Dang and B. A. Morrow, J. Phys. Chem., 1995, 99, 14444-14449.

43 G. Busca, Phys. Chem. Chem. Phys., 1999, 1, 723-736.

44 B. A. Morrow and A. J. McFarlan, Langmuir, 1991, 7, 1695-1701.

45 T. Simanouchi, Tables of Molecular Vibrational Frequencies Consolidated, U. S. Natl. Bur. Stand., 1972.

46 H. Schnöckel, Angew, Chem., 1980, 92, 310-313.

47 A. Datta, R. G. Cavell, R. W. Tower and Z. M. George, J. Phys. Chem., 1985, 89, 443-449.

48 V. Ermini, E. Finocchio, S. Sechi, G. Busca and S. Rossini, Appl. Catal. A: General, 2000, 190, 157-167.

49 P.-A. Carlsson, S. Mollner, K. Arnby and M. Skoglundh, Chem. Eng. Sci., 2004, 59, 4313-4323.

50 O. Saur, M. Benistel, A. B. M. Saad, J. C. Lavalley, C. P. Tripp and B. A. Morrow, J. Catal., 1986, 99, 104-110.

51 M. B. Mitchell, V. N. Sheinker and M. G. White, J. Phys. Chem., 1996, 100, 7550-7557.

52 S. R. Ryu, I. Noda and Y. M. Jung, Appl. Spectros., 2010, 64, 1017-1021.

53 M. Waqif, P. Bazin, O. Saur, J. Lavalley, G. Blanchard and O. Touret, Appl. Catal. B: Environ., 1997, 11, 193-205.

54 P. Bazin, O. Saur, J. C. Lavalley, G. Blanchard, V. Visciglio and O. Touret, Appl. Catal. B: Environ., 1997, 13, 265-274.

55 T. Luo and R. J. Gorte, Appl. Catal. B: Environ., 2004, 53, 77-85.

56 C. Binet, A. Badri and J. C. Lavalley, J. Phys. Chem., 1994, 98, 63926398.

57 F. Bozon-Verduraz and A. Bensalem, J. Chem. Soc. Faraday Trans., 1994, 90, 653-657.

58 T. Shido and Y. Iwasawa, J. Catal., 1992, 136, 493-503.

59 C. Li, Y. Sakata, T. Arai, K. Domen, K. I. Maruya and T. Onishi, J. Chem. Soc. Faraday Trans., 1989, 85, 929-943.

60 W. L. C. Li, Y. Chen and Q. Xin, Stud. Surf. Sci. Catal., 1993, 77, $217-$ 222.

61 E. Odier, Y. Schuurman and C. Mirodatos, Catal. Today, 2007, 127, 230237.

62 B. R. Cuenya, Thin Solid Films, 2010, 518, 3127-3150.

63 Y. Yazawa, N. Kagi, S. Komai, A. Satsuma, Y. Murakami and T. Hattori, Catal. Lett., 2001, 72, 157-160.

64 Y. Yazawa, N. Takagi, H. Yoshida, S. Komai, A. Satsuma, T. Tanaka, S. Yoshida and T. Hattori, Appl. Catal. A: General, 2002, 233, 103-112.

65 A. P. Elg, F. Eisert and A. Rosén, Surf. Sci., 1997, 382, 57-66.

66 D. T. P. Watson, J. van Dijk, J. J. W. Harris and D. A. King, Surf. Sci., 2002, 506, 243-250.

67 P. Mariaudeau, J. F. Dutel, M. Dufaux and C. Naccache, Metal-Support and Metal-Additive Effects in Catalysis, Elsevier, 2002, pp. 95-104.

68 W. Tang, Z. Hu, M. Wang, G. D. Stucky, H. Metiu and E. W. McFarland, J. Catal., 2010, 273, 125-137.

69 P.-A. Carlsson and M. Skoglundh, Appl. Catal. B: Environ., 2011, 101, 669-675.

70 R. Poisson, J. P. Brunelle and P. Nortier, Catalyst Supports and Supported 
Catalysts Technology and Applied Concepts, Butterworths, A.B. Stiles edn, 1987, p. 11.

71 E. Xue, K. Seshan and J. R. H. Ross, Appl. Catal. B: Environ., 1996, 11, 65-79.

72 T. Wang, A. Vazquez, A. Kato and L. D. Schmidt, J. Catal., 1982, 78, 306-318.

73 H. S. Gandhi and M. Shelef, Appl. Catal., 1991, 77, 175-186.

74 S. Astegger and E. Bechtold, Surf. Sci., 1982, 122, 491-504.

75 M. Happel, L. Kylhammar, P.-A. Carlsson, J. Libuda, H. Grönbeck and
M. Skoglundh, Appl. Catal. B: Environ., 2009, 91, 679-682.

76 W. Xu, R. Si, S. D. Senanayake, J. Llorca, H. Idriss, D. Stacchiola, J. C. Hanson and J. A. Rodriguez, J. Catal., 2012, 291, 117-126.

77 M. A. Newton, M. D. Michiel, A. Kubacka and M. Fernández-García, J. Am. Chem. Soc., 2010, 132, 4540-4541.

78 M. A. Newton, M. D. Michiel, A. Kubacka, A. Iglesias-Juez and M. Fernández-García, Angew. Chem. Int. Ed., 2012, 51, 2363-2367.

79 M. Y. Smirnov, A. V. Kalinkin, A. V. Pashis, A. M. Sorokin, A. S. Noskov, K. C. Kharas and V. I. Bukhtiyarov, J. Phys. Chem. B, 109, 109, 1171211719. 